\title{
Projected Significant Increase in the Number of Extreme Extratropical Cyclones in the Southern Hemisphere ${ }^{\mathscr{O}}$
}

\author{
EDMUND K. M. CHANG \\ School of Marine and Atmospheric Sciences, Stony Brook University, State University of New York, \\ Stony Brook, New York
}

(Manuscript received 26 July 2016, in final form 13 December 2016)

\begin{abstract}
Extratropical cyclones are responsible for much of the extreme weather in the midlatitudes; thus, how these cyclones may change under increasing greenhouse gas forcing is of much general interest. Previous studies have suggested a poleward shift in the location of these cyclones, but how the intensity may change remains uncertain, especially in terms of maximum wind speed. In this study, projected changes in extreme cyclones in the Southern Hemisphere, based on 26 models participating in phase 5 of the Coupled Model Intercomparison Project (CMIP5), are presented. Multiple definitions of extreme cyclones have been examined, including intensity exceeding constant thresholds of sea level pressure perturbations, 850 -hPa vorticity, and 850-hPa winds, as well as variable thresholds corresponding to a top- 5 or top- 1 cyclone per winter month in these three parameters and the near-surface winds. Results presented show that CMIP5 models project a significant increase in the frequency of extreme cyclones in all four seasons regardless of the definition, with over $88 \%$ of the models projecting an increase. Spatial patterns of increase are also consistent, with the largest increase projected between $45^{\circ}$ and $60^{\circ} \mathrm{S}$, extending from the South Atlantic across the south Indian Ocean into the Pacific. The projected increases in cyclone statistics are consistent with those in Eulerian statistics, such as sea level pressure (SLP) variance. However, while the projected increase in SLP variance can be linked to increase in the mean available potential energy (MAPE), the increases in cyclone statistics are not well correlated with those in MAPE.
\end{abstract}

\section{Introduction}

Extratropical cyclones form an important part of the global circulation. They are responsible for much of the high-impact weather in the midlatitudes, including heavy precipitation (Pfahl and Wernli 2012; Catto et al. 2015), strong winds (Ashley and Black 2008), and coastal storm surges (Colle et al. 2008). They are also the surface manifestation of baroclinic waves that are responsible for much of the transport of momentum, heat, and moisture in the midlatitudes (e.g., Peixoto and Oort 1992). Thus, how these storms will change in the future is of much general interest. In particular, how the frequency of the extreme cyclones change is of most concern, since they are the ones that cause the most damage. Many previous studies have suggested

Supplemental information related to this paper is available at the Journals Online website: http://dx.doi.org/10.1175/ JCLI-D-16-0553.s1.

Corresponding author: Dr. Edmund K. M. Chang, kar.chang@ stonybrook.edu that cyclone-related extreme precipitation may increase under global warming (e.g., Bengtsson et al. 2009; Zappa et al. 2013), but how extreme winds may change is still rather uncertain (Christensen et al. 2013). Hence, we will not examine precipitation change in this study.

Numerous studies have examined the climatology and variability of the Southern Hemisphere ( $\mathrm{SH}$ ) storm tracks using various reanalysis datasets (e.g., Simmonds and Keay 2000; Lim and Simmonds 2002; Hoskins and Hodges 2005; Wei and Qin 2016; Wang et al. 2016). Most showed that in summer the distribution is rather annular, while during the other seasons the distribution is a bit more asymmetric, with the storm-track maximum spiraling poleward from the Atlantic across the Indian Ocean into the Pacific. Readers are referred to these studies for more details.

Being part of a baroclinic wave, a cyclone derives its energy from the mean available potential energy (MAPE) associated with the equator-to-pole temperature gradient (e.g., Lorenz 1955). O'Gorman (2010) suggested that, under global climate change, climate-model-projected storm-track response in terms of eddy kinetic energy (EKE) is directly proportional to model-projected change 
in the MAPE. Under increasing greenhouse gas forcing, static stability is expected to increase as a result of enhanced warming in the upper troposphere. This will lead to a decrease in the MAPE and potentially a decrease in cyclone activity (e.g., Lim and Simmonds 2009). On the other hand, upper-tropospheric temperature gradient is expected to increase as a result of warming in the tropical upper troposphere and cooling in the polar lower stratosphere, leading to an overall increase in the MAPE in the SH (O'Gorman 2010) and an overall increase in EKE, especially in the upper troposphere (Yin 2005; O'Gorman 2010; Chang et al. 2012). In addition, latent heat release in the warm sector of cyclones provides an additional source of energy to cyclone development. With projected increase in temperature, the amount of moisture in the atmosphere is expected to increase, potentially giving rise to more intense cyclones (e.g., Willison et al. 2013).

Apart from possible changes in storm-track intensity, climate models also project a robust poleward shift of the midlatitude jet and storm track (Yin 2005), especially in the SH. While a poleward shift has been observed in the SH (Thompson and Solomon 2002), much of the historical shift in summer and spring is likely caused by ozone depletion (Orlanski 2013). Ozone recovery during the first half of the twenty-first century is expected to slow down this projected poleward shift during the SH summer (Polvani et al. 2011; Barnes et al. 2014), especially under scenarios in which greenhouse gas increase is slowed, but the poleward migration of the $\mathrm{SH}$ jet and storm track is expected to occur during other seasons, as well as in summer under high-emission scenarios after the ozone level has stabilized (Chang et al. 2012; Barnes et al. 2014).

While the projection of a poleward shift of the SH storm track and cyclone activity is widely accepted, together with a small decrease in the total number of extratropical cyclones, as discussed in the Fifth Assessment Report (AR5) of the Intergovernmental Panel on Climate Change (IPCC) (see Collins et al. 2013; Christensen et al. 2013), projected change in cyclone intensity is still rather uncertain (e.g., Ulbrich et al. 2009). Several studies have suggested that cyclone intensity, in terms of absolute value of sea level pressure (SLP) minima (e.g., Lambert and Fyfe 2006) or SLP perturbations (Chang et al. 2012), is projected to increase under global warming. Grieger et al. (2014), examining an ensemble of seven coupled model simulations, also suggested a modest increase in the frequency of strong cyclones as defined by the Laplacian of SLP. However, other studies, such as Bengtsson et al. (2009) and Zappa et al. (2013), found no increase in wind speed around extratropical cyclones (ETCs). Christensen et al. (2013, p. 1252) stated that "the CMIP5 model projections show little evidence of change in the intensity of winds associated with ETCs." Nevertheless, note that Bengtsson et al. (2009) only examined simulations based on one model, and Zappa et al. (2013) only examined cyclones in the North Atlantic.

It is difficult to directly compare the results of the different studies discussed in the previous paragraph, since different ensembles of simulations were examined, and different studies defined cyclone intensity in different ways. In this study, phase 5 of the Coupled Model Intercomparison Project (CMIP5; Taylor et al. 2012) multimodel ensemble will be examined. Multiple parameters will be used to indicate cyclone intensity, including SLP perturbations, vorticity perturbations, and near-cyclone maximum wind speed. Results of this study show that under the high-emission representative concentration pathway 8.5 (RCP8.5) scenario, CMIP5 models project significant increase in the frequency of extreme extratropical cyclones in the $\mathrm{SH}$ in all four seasons, regardless of how cyclone intensity is defined.

The data and methods will be introduced in section 2 . In section 3, results for SH winter will be presented. Results for the other seasons will be examined in section 4 , followed by some discussions in section 5 and a summary and conclusions in section 6.

\section{Data and methods}

\section{a. Data}

Reanalysis data from the European Centre for Medium-Range Weather Forecasts (ECMWF) interim reanalysis (ERA-Interim; Dee et al. 2011) are used as a reference to compare with climate model simulations of historical cyclone activity. Variables examined include 6-hourly SLP, 850-hPa wind, and 10-m wind. Historical and future-time simulations from 26 CMIP5 models (see Table S1 in the supplemental material) have been analyzed to examine the projected change in cyclone activity. These represent all models from which all the needed 6-hourly and monthly pressure level data were available from the CMIP5 archives at the time the analyses were performed. As in Chang et al. (2012), projected change is based on the difference between the end of the twenty-first century (2081-2100), taken from the high-emission RCP8.5 simulations, and the end of the twentieth century (1980-99), taken from the historical simulations. All 26 models provide 6-hourly SLP and 850-hPa wind data. However, most CMIP5 models do not provide data for $10-\mathrm{m}$ wind. A majority of the models (19 models) do provide 6-hourly model level wind data, and the wind from the lowest model level is used to represent near-surface wind (see Table $\$ 2$ in the 
supplemental material). For each model, data from a single simulation is examined; usually the r1i1p1 run is chosen, but for CCSM4 the r6i1p1 run is used. Monthly mean temperature and wind data at multiple pressure levels are used to examine projected changes in the large-scale flow.

\section{b. Cyclone statistics}

Cyclone tracking is performed on a monthly basis using the objective tracking algorithm of Hodges (1999), which has been used in many previous studies (e.g., Hoskins and Hodges 2002; Bengtsson et al. 2009; Chang et al. 2012). In this study, two definitions of cyclones are considered: minima in SLP and 850-hPa relative vorticity (note that, in the $\mathrm{SH}$, relative vorticity is negative for cyclones). Following Hoskins and Hodges (2002), for $850-\mathrm{hPa}$ relative vorticity, to focus on synoptic-scale mobile cyclones, both large- and small-spatial-scale features are removed, and only scales equivalent to a spherical harmonic triangular truncation of between T5 and T42 are kept. For SLP, following Chang et al. (2012) and Chang (2014), both large-spatial-scale (total wavenumber less than T5) and the monthly mean SLP are removed. Previous studies (e.g., Chang 2014) have shown that cyclone statistics based on SLP may be strongly influenced by changes in the large-scale flow. Also note that many previous studies have suggested removing the background large-scale flow when examining SH intense cyclones (e.g., Sinclair 1995; Lim and Simmonds 2002; Simmonds et al. 2003). While statistics based on $850-\mathrm{hPa}$ vorticity are expected to be less dependent on the large-scale flow, Colle et al. (2013) found that many vorticity centers do not have an associated SLP minimum. Indeed, we found many more tracks based on 850-hPa vorticity than based on SLP; for example, based on ERA-Interim data, during SH winter [June-August (JJA)] there are, on average, 122 cyclone tracks per month based on tracking $850-\mathrm{hPa}$ vorticity and about 90 cyclone tracks per month based on SLP. Comparing statistics based on these two different definitions of cyclones will provide insights regarding the robustness of the results.

All reanalysis and CMIP5 model data are first interpolated onto a common $2.5^{\circ} \times 2.5^{\circ}$ latitude-longitude grid before spatial filtering and tracking. To focus on mobile cyclones, following Hoskins and Hodges (2002), only tracks that last at least two days (eight 6-hourly time steps) and with displacement from starting to end point larger than $1000 \mathrm{~km}$ are retained. Previous studies (e.g., Raible et al. 2008; Neu et al. 2013; Ulbrich et al. 2013) have suggested that, while there are uncertainties in cyclone statistics arising from different detection and tracking methods, the statistics of strong cyclones are more robust. Here, since we focus on the statistics of extreme cyclones, we expect that our results should not be very sensitive to the tracking algorithm used.

Several different definitions are used to define extreme cyclones. First, a fixed common threshold is used. For extreme SLP cyclones, cyclone statistics based on tracking SLP anomalies are used. Following Chang et al. (2012), a threshold of $-40 \mathrm{hPa}$ is used. About $2.6 \mathrm{cy}-$ clones per winter month in the $\mathrm{SH}$ exceed this threshold based on ERA-Interim data (Table 1). For $850-\mathrm{hPa}$ relative vorticity, statistics based on tracking $850-\mathrm{hPa}$ vorticity anomalies are used, and the threshold for an extreme cyclone is $-1.1 \times 10^{-4} \mathrm{~s}^{-1}$. About 5.3 cyclones in the $\mathrm{SH}$ exceed this threshold each winter month. We have also examined the maximum wind at $850 \mathrm{hPa}$ (see, e.g., Zappa et al. 2013) within a $5^{\circ}$ great circle $(555 \mathrm{~km})$ of a cyclone center. A threshold of $45 \mathrm{~m} \mathrm{~s}^{-1}$ is used for 850-hPa winds, corresponding to about 5 cyclones per winter month. To find the maximum wind near a cyclone center, the wind data is used at the native resolution provided by each model. Here, the $850-\mathrm{hPa}$ extreme winds have been matched to cyclones tracked based on $850-\mathrm{hPa}$ relative vorticity. We have also matched 850-hPa extreme winds to cyclones tracked based on SLP, and overall results are consistent.

For maximum near-surface winds near the cyclone center, since the height of the lowest model level provided by each model differs significantly (see Table S2), ranging from $10 \mathrm{~m}$ to a hybrid-sigma level of 0.9926 (about $60 \mathrm{~m}$ above the surface), using a fixed threshold across all models is not reasonable. Thus, for each model, we use a threshold that corresponds to the top-5 cyclones per winter month during the historical period. The threshold for each model is listed in Table S4 of the supplemental material. Extreme near-surface winds have been matched to cyclones tracked based on SLP anomalies, but results based on matching to cyclones tracked based on $850-\mathrm{hPa}$ vorticity maxima are very similar.

Grieger et al. (2014) defined extreme cyclones based on a top-5-percentile threshold of the Laplacian of SLP for each model. ${ }^{1}$ Here, we instead use a threshold for the top-5 cyclones per month (more accurately top 300 over 20 winter seasons), since the total number of cyclones simulated by each model differs quite substantially, ranging from 73 to 122 per month for SLP cyclones in JJA and from 108 to 169 per month for cyclones defined

\footnotetext{
${ }^{1}$ Note that, based on the definition of Grieger et al. (2014), there are about 40 such cyclones each year in the SH. Based on the definition used in this study (Table 1), in CMIP5 simulations the numbers of strong vorticity cyclones, as well cyclones with strong $850-\mathrm{hPa}$ and near-surface winds, are similar. In addition, the frequencies of top-5 cyclones (see Table S5) are also similar.
} 
TABLE 1. Climatology (1980-99) and projected change (2081-2100 minus 1980-99) of extreme cyclones defined based on four different definitions. The climatology and change are quantified by number of cyclones per month, except that the rightmost column shows the projected change in percent. The uncertainty ranges correspond to the $95 \%$ confidence interval based on a two-tailed Student's $t$ test.

\begin{tabular}{|c|c|c|c|c|}
\hline & \multirow[b]{2}{*}{ ERA-I Climatology } & \multicolumn{3}{|c|}{ CMIP5 } \\
\hline & & Climatology & Change & $\%$ change \\
\hline \multicolumn{5}{|c|}{ Deep cyclones $(\mathrm{SLP}>40 \mathrm{hPa})$} \\
\hline SH winter & 2.62 & 1.82 & $0.72 \pm 0.21$ & $52 \pm 16$ \\
\hline SH spring & 1.68 & 1.2 & $0.59 \pm 0.18$ & $55 \pm 16$ \\
\hline SH summer & 0.6 & 0.52 & $0.22 \pm 0.07$ & $55 \pm 26$ \\
\hline $\mathrm{SH}$ fall & 1.57 & 1.21 & $0.44 \pm 0.15$ & $45 \pm 16$ \\
\hline \multicolumn{5}{|c|}{ Strong cyclones $\left(\right.$ vorticity $\left.>11 \times 10^{-5} \mathrm{~s}^{-1}\right)$} \\
\hline SH winter & 5.3 & 4.49 & $0.90 \pm 0.32$ & $29 \pm 10$ \\
\hline SH spring & 3.1 & 3.04 & $0.88 \pm 0.24$ & $32 \pm 9.2$ \\
\hline SH summer & 2.78 & 2.09 & $0.27 \pm 0.13$ & $18 \pm 9.2$ \\
\hline $\mathrm{SH}$ fall & 4.27 & 3.56 & $0.23 \pm 0.19$ & $9.0 \pm 6.9$ \\
\hline \multicolumn{5}{|c|}{ Strong cyclones $\left(850\right.$ wind $\left.>45 \mathrm{~m} \mathrm{~s}^{-1}\right)$} \\
\hline SH winter & 4.95 & 5.69 & $1.12 \pm 0.39$ & $46 \pm 20$ \\
\hline SH spring & 2.33 & 3.15 & $0.86 \pm 0.31$ & $41 \pm 19$ \\
\hline SH summer & 1.4 & 1.22 & $0.47 \pm 0.18$ & $73 \pm 33$ \\
\hline SH fall & 3.25 & 3.2 & $0.77 \pm 0.22$ & $42 \pm 14$ \\
\hline \multicolumn{5}{|c|}{ Strong cyclones (top-5 JJA surface wind per month) } \\
\hline SH winter & 5 & 5 & $0.86 \pm 0.64$ & $19 \pm 13$ \\
\hline SH spring & 2.96 & 2.95 & $0.59 \pm 0.52$ & $21 \pm 14$ \\
\hline SH summer & 2.2 & 1 & $0.21 \pm 0.11$ & $25 \pm 17$ \\
\hline $\mathrm{SH}$ fall & 4.07 & 3.2 & $0.35 \pm 0.28$ & $9.7 \pm 8.2$ \\
\hline
\end{tabular}

as 850 -hPa vorticity minima. We believe that using a threshold for the same number of cyclones for each model is easier to interpret. Apart from near-surface winds, we have also used the top-5 threshold in terms of SLP, $850-\mathrm{hPa}$ vorticity, and $850-\mathrm{hPa}$ maximum wind. We have also examined statistics of even more extreme cyclones, corresponding to the top- 1 for each winter month. All these thresholds for each model are listed in Tables S3 and S4 of the supplemental material.

For each definition of extreme cyclones, we examine the average number of cyclone tracks per month for each season for the historical period and future projection. Each cyclone track that exceeds the threshold is counted only once. To display spatial distribution, the frequency of occurrence of cyclone centers that exceed the threshold within $500 \mathrm{~km}$ of the center of each grid box is displayed. In this case, each instance that a cyclone center exceeds the threshold is counted, so a single cyclone track can be counted multiple times. This measure is similar to the feature density of Hoskins and Hodges (2002).

\section{c. Eulerian indices}

Apart from Lagrangian cyclone track statistics, since Blackmon (1976), many studies have used Eulerian variance and covariance statistics to represent storm-track activity. Since passages of cyclones generate large pressure changes, pressure tendency has been widely used as a measure to quantify cyclone activity (e.g., Alexander et al. 2005; Feser et al. 2015). Following Chang et al. (2015), the following metric is defined to indicate extratropical cyclone activity (ECA):

$$
\operatorname{ECApp}=\overline{[\operatorname{SLP}(t+24 \mathrm{~h})-\operatorname{SLP}(t)]^{2}} .
$$

In (1), ECApp (shortened to pp in figures) is ECA defined by the variance of the SLP tendency. The average is usually taken over a month or a season at each grid box. This measure can also be regarded as the variance of temporally filtered SLP data, with half-power points at 1.2 and 6 days (see Wallace et al. 1988). Chang and Fu (2002) have shown that statistics based on this filter are similar to statistics derived from other bandpass filters that retain the synoptic time scale.

Since we are interested in cyclones that generate extreme winds, it is also of interest to examine how the frequency of occurrence of these winds changes. Hence, we have also examined the frequency of $850-\mathrm{hPa}$ wind speed over $45 \mathrm{~m} \mathrm{~s}^{-1}$ at each grid box. Based on ERA-Interim data, during $\mathrm{SH}$ winter between $30^{\circ}$ and $60^{\circ} \mathrm{S}$, about $58 \%$ of these winds occur within $555 \mathrm{~km}$ of tracked cyclone centers, 
and $78 \%$ occur within $1110 \mathrm{~km}$. Thus, most of the occurrences of these high winds are associated with cyclones.

\section{Results for JJA}

\section{a. Eulerian statistics}

\section{1) ECAPP}

Climatology of ECApp for SH winter based on $20 \mathrm{yr}$ (1980-99) of ERA-Interim data is shown in Fig. 1a. Given that the CMIP5 multimodel mean is smoothed significantly due to averaging over climatologies from 26 models, all the ERA-Interim climatologies have been smoothed using a 9-point spatial filter for better visual comparison. Note that the unsmoothed JJA climatologies are shown in Fig. S1 of the supplemental material for reference. Consistent with previous studies, maximum cyclone activity extends from the South Atlantic around $55^{\circ} \mathrm{S}$ across the south Indian Ocean and then spirals poleward into the South Pacific. The CMIP5 multimodel mean (Fig. 1b) is consistent, but the peaks are slightly weaker.

The CMIP5 multimodel mean projected change is shown in Fig. 1c. In this and similar plots, the shades show the number of models projecting the same sign of change over each grid box. If the sign of the projected change by each model is random, 18 or more out of 26 models projecting the same sign has a (two tailed) probability of $7.5 \%$, while 20 or more models projecting the same sign has a probability of $<1 \%$. However, apart from ECApp, for which every model projects either positive or negative change at all grid boxes, for all other statistics, there are many grid boxes over which some models do not have any occurrence of that particular extreme statistic during both the historical and future periods and hence does not provide any projection over that grid box. In other words, for these statistics, 16 models projecting positive change does not necessarily mean that the remaining 10 models project negative change. This should be kept in mind when assessing model agreement over regions where the climatological frequency is low.

Similar to the climatology, maximum increase in ECApp also extends from the South Atlantic across the south Indian Ocean into the South Pacific, with the maximum increase projected over the south Indian Ocean near $90^{\circ} \mathrm{E}$. Consistent with previous studies (e.g., Chang et al. 2012), near the surface, Eulerian stormtrack statistics mainly indicate an increase of storm-track activity during the $\mathrm{SH}$ winter. There are some indications of decrease in storm-track activity in the subtropical Indian and Pacific Oceans, but the magnitude of the decrease is small compared to the magnitude of increase farther south.

Projected percentage change by each model, averaged over $30^{\circ}-60^{\circ} \mathrm{S}$, is shown in Fig. 2a. The identities of the models can be found in Table S1. Of the 26 models, 25 project an increase in this measure, with a number of models projecting an increase of over $20 \%$.

\section{2) FREQUENCY OF 850 WINDS OVER $45 \mathrm{M} \mathrm{s}^{-1}$}

The threshold of $45 \mathrm{~m} \mathrm{~s}^{-1}$ is chosen because, on average, about 5 cyclones per winter month have winds exceeding this threshold between $30^{\circ}$ and $60^{\circ} \mathrm{S}$ (Table 1 ). Climatology based on ERA-Interim $1.5^{\circ} \times 1.5^{\circ}$ data, linearly interpolated onto a $2.5^{\circ} \times 2.5^{\circ}$ grid and spatially smoothed, is shown in Fig. 1d. This particular grid resolution is chosen since it is within the range of resolution of CMIP5 models and is similar to the resolution of the higher-resolution models (see Table S2). The frequency is displayed as the percentage of time $850-\mathrm{hPa}$ wind speed is over the threshold at each grid box. We can clearly see a band of maxima extending from the South Atlantic across the south Indian Ocean to south of Australia, with maximum frequency reaching over $0.1 \%$ in the South Atlantic and a weaker maximal region over the South Pacific between New Zealand and South America.

Climatology based on CMIP5 models is shown in Fig. 1e. For each model, the frequency exceeding this threshold is first computed on its own model grid, and the spatial distribution is then interpolated onto a common $2.5^{\circ} \times 2.5^{\circ}$ grid before averaging. These results are much smoother than the unsmoothed ERA-Interim climatology (Fig. S1d) since this is an average over 26 model climatologies. Overall, CMIP5 models show an underestimation of the frequency in the South Atlantic and overestimation over the south Indian and South Pacific Oceans, with the maximum occurring over the south Indian Ocean instead of the South Atlantic.

Future change projected by the multimodel mean is shown in Fig. 1f. Similar to ECApp, the projected change is dominated by a band of increase extending from the South Atlantic across the south Indian Ocean into the South Pacific, with maximum increase over the Indian Ocean near $60^{\circ} \mathrm{E}$. There is high model agreement in the South Atlantic and Indian Oceans but less model agreement over the South Pacific. This is because these events are very rare over the South Pacific. Note that a frequency of occurrence of $0.02 \%$ corresponds to a total of 1.5 events at that grid box over the entire 20-winter period for 6-hourly data. Thus, many models do not have a single occurrence of these high-wind events in many grid boxes over the South Pacific. However, averaged over the region $30^{\circ}-60^{\circ} \mathrm{S}, 180^{\circ}-75^{\circ} \mathrm{W}, 25$ of the 26 


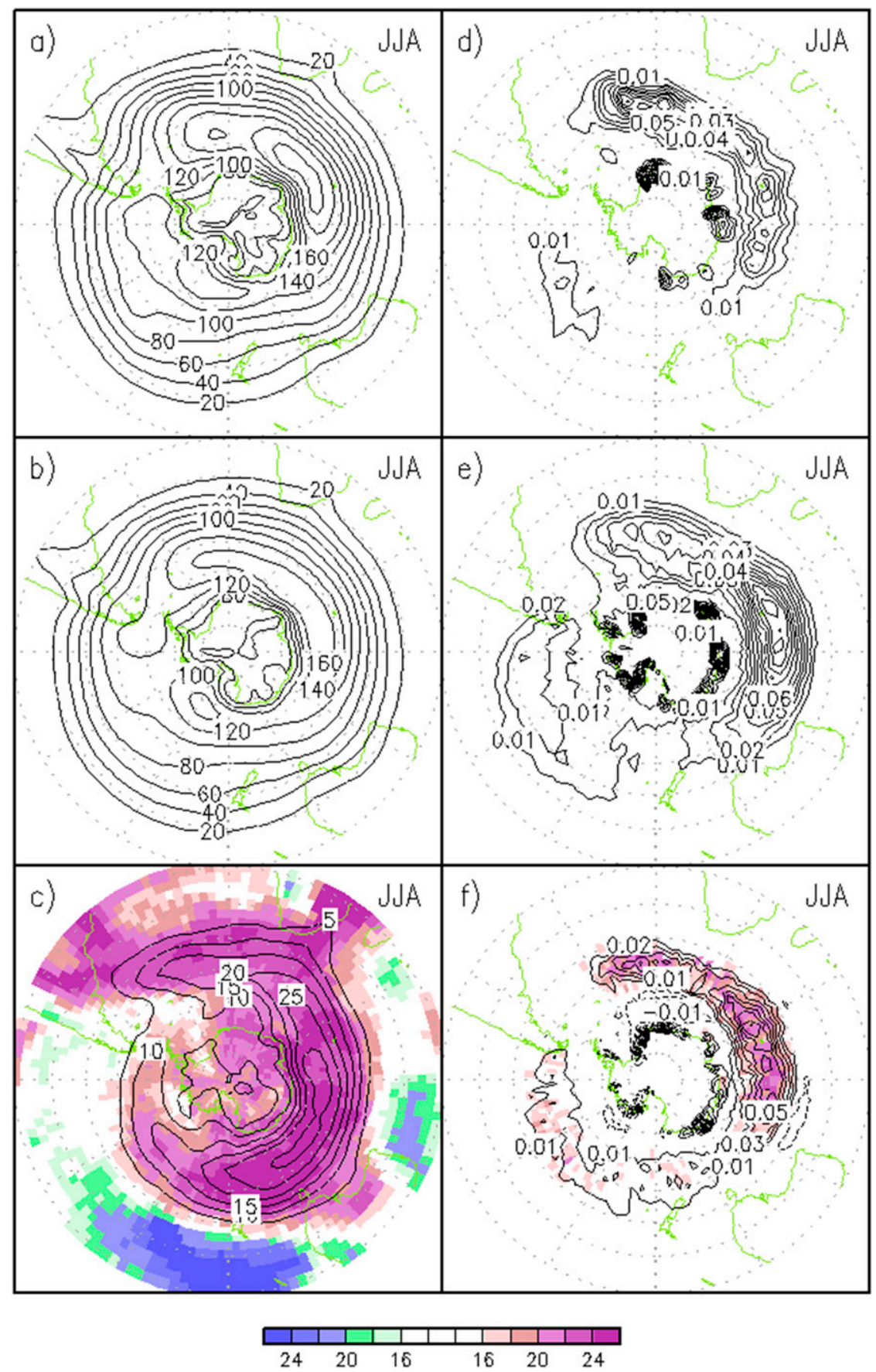

FIG. 1. (a) ECApp climatology based on ERA-Interim data, for JJA of 1980-99 (contour interval $20 \mathrm{hPa}^{2}$ ). (b) As in (a), but based on ensemble mean of 26 CMIP5 models. (c) Projected difference in CMIP5 ensemble mean ECApp for JJA between 2081-2100 and 1980-99 (contour interval $\left.5 \mathrm{hPa}^{2}\right)$. (d) Climatological frequency of extreme $850-\mathrm{hPa}$ winds $\left(>45 \mathrm{~m} \mathrm{~s}^{-1}\right)$ in JJA based on ERA-Interim data (contour interval $0.01 \%$ ) interpolated to a $2.5^{\circ} \times 2.5^{\circ}$ lat-lon grid. (e) As in (d), but from CMIP5 multimodel ensemble mean. (f) Projected difference in frequency of extreme 850-hPa winds for JJA between the end of 2081-2100 and 1980-99. Note that the zero contour has been left out in the plots. The color shades in (c) and (f) show the number of models projecting the same sign of change, with warm colors showing the number of models with positive change, and cool colors negative change. The ERA-Interim climatologies shown in $(\mathrm{a})$ and $(\mathrm{d})$ have been smoothed using a 9-point $(3 \times 3)$ spatial filter. 
a) Individual model \% change in pp (JJA 30-60S)

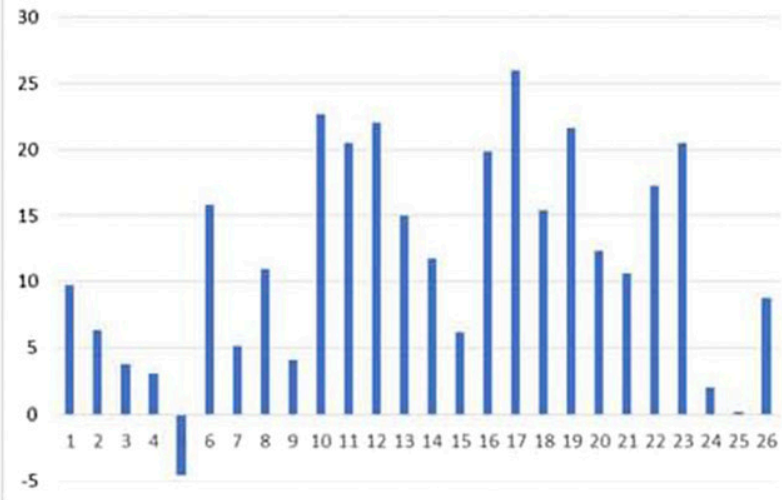

b) Individual model \% change in freq of extreme 850 winds (JJA 30-60S)

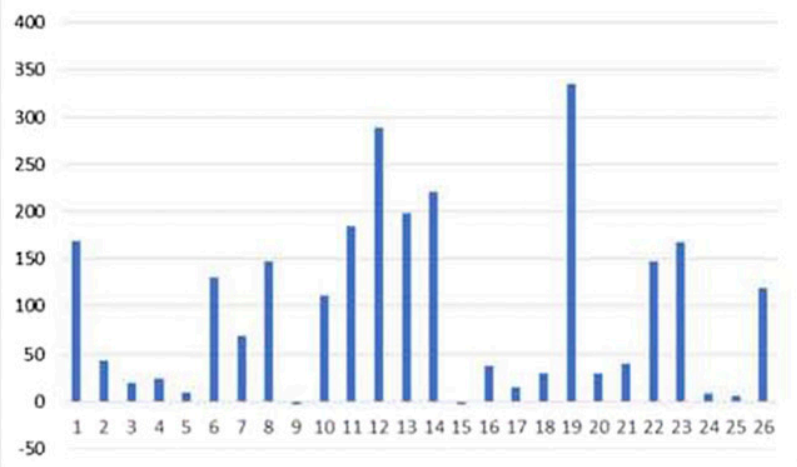

c) Individual model \% change in \# extreme SLP cyclones (JJA 30-60S)

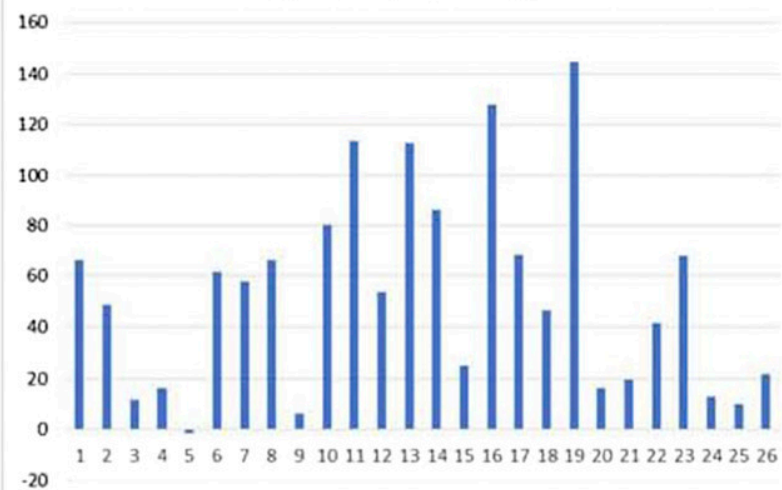

d) Individual model \% change in \# of extreme 850 vorticity cyclones (JJA 30-60S)

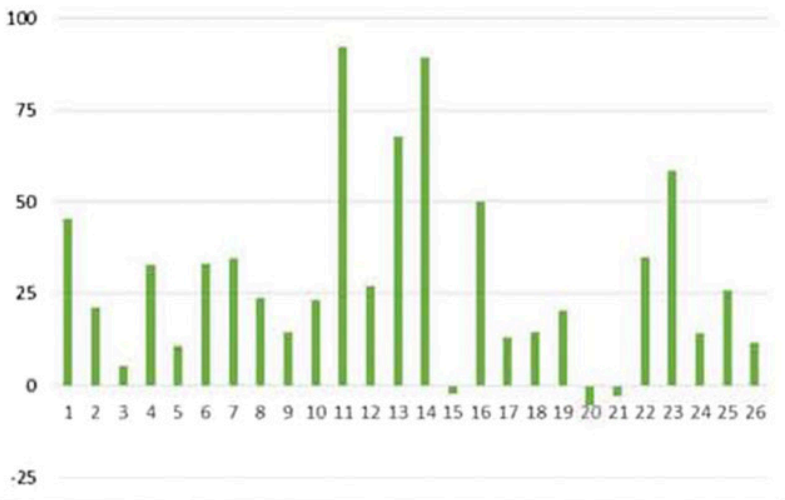

e) Individual model \% change in \# extreme 850 wind cyclones (JJA 30-60S)

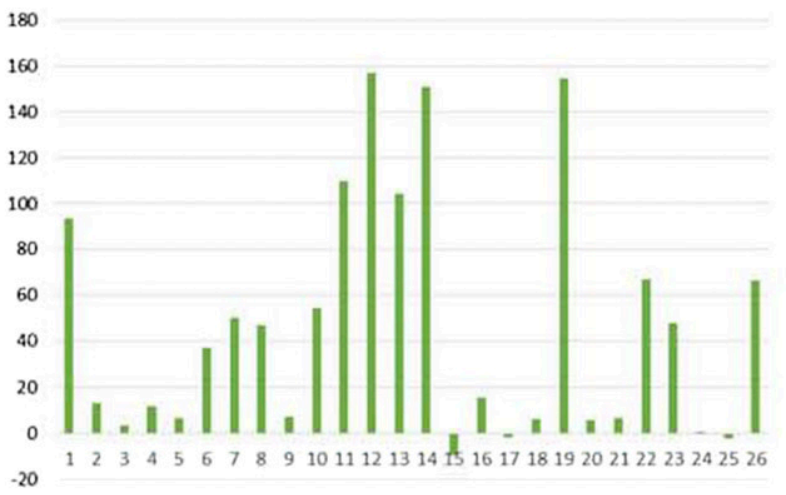

f) Individual model \% change in \# extreme near surface wind cyclones (JJA 30-60S)

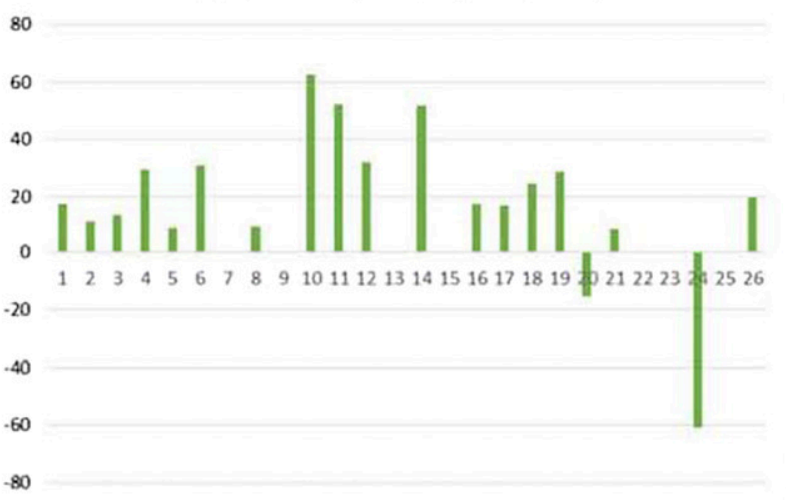

FIG. 2. Projected percentage change for individual models for JJA between 2081-2100 and 1980-99 averaged between $30^{\circ}$ and $60^{\circ} \mathrm{S}$ for (a) ECApp; (b) frequency of extreme $850-\mathrm{hPa}$ winds $\left(>45 \mathrm{~m} \mathrm{~s}^{-1}\right)$; (c) number of extreme SLP cyclones (SLP perturbation $<-40 \mathrm{hPa}$ ); (d) number of extreme cyclones in terms of 850-hPa vorticity (vorticity perturbation $<-1.1 \times 10^{-4} \mathrm{~s}^{-1}$ ); (e) number of cyclones with extreme 850 -hPa winds $\left(>45 \mathrm{~m} \mathrm{~s}^{-1}\right)$; and (f) number of cyclones with extreme near-surface winds (equivalent to a top-5 cyclone in a JJA month).

models project increase in the frequency of extreme winds, indicating that, while the pattern of increase may not be robust, there is strong model consensus on the overall increase over the Pacific.
Note that in this figure (as in all other figures displaying changes except for those for ECApp), the contour interval is the same as that used in displaying the climatology, indicating that the projected increase has similar 
magnitude as the climatology over most regions. Indeed, 12 of the 26 models project more than $100 \%$ increase over $30^{\circ}-60^{\circ} \mathrm{S}$ (Fig. $2 \mathrm{~b}$ ), with the multimodel mean percentage change projected to be $98 \%$. We have also examined the frequency of $850-\mathrm{hPa}$ winds exceeding $50 \mathrm{~m} \mathrm{~s}^{-1}$, and its frequency of occurrence is projected to increase by a multimodel mean of $148 \%$ under RCP8.5.

Figure $1 \mathrm{f}$ indicates that high-wind frequency may decrease close to Antarctica, especially near the eastern part of the Ross Sea and the Weddell Sea. However, the projected decreases are mainly due to projections by the two Meteorological Research Institute (MRI) models and are not robust features across the multimodel ensemble.

\section{b. Cyclone statistics}

Before discussing the statistics of extreme cyclones, we mention here that, consistent with previous studies, nearly all CMIP5 models project a decrease in the total number of cyclones in the midlatitude $\mathrm{SH}$ (between $30^{\circ}$ and $60^{\circ} \mathrm{S}$ ). The multimodel mean decrease amounts to around $-6 \%$ in all four seasons, regardless of whether the tracking is based on minima in SLP or in $850-\mathrm{hPa}$ vorticity. Note that several studies (Pezza et al. 2007; Wang et al. 2016) have found decreasing trends in the number of SH cyclones in multiple reanalysis datasets. Meanwhile, Pezza et al. (2012) and Rudeva and Simmonds (2015) found poleward shift of cyclones and frontal activity during the austral summer.

\section{1) EXTREME SLP CYCLONES}

Based on ERA-Interim data, between 1980 and 1999, there are, on average, 2.6 cyclones per month in $\mathrm{SH}$ winters that have filtered SLP perturbations reaching $-40 \mathrm{hPa}$ or lower between $30^{\circ}$ and $60^{\circ} \mathrm{S}$. The spatial distribution of these cyclones is shown in Fig. 3a, which shows a band of maximum activity around Antarctica extending from east of the southern part of South America across the South Atlantic, south Indian Ocean, and the South Pacific. The strongest activity lies in the South Atlantic, while the weakest activity is south of Australia and New Zealand. The CMIP5 multimodel mean climatology is shown in Fig. 3b. Model-simulated cyclones do not extend as far north as observed over the South Atlantic. In addition, overall CMIP5 models underestimate the number of extreme SLP cyclones by about $30 \%$ (see Table 1), with clear underestimations over the Indian Ocean and southeastern Pacific.

Projected percentage increase in the number of these cyclones for each model over the SH midlatitudes $\left(30^{\circ}-60^{\circ} \mathrm{S}\right)$ is shown in Fig. 2c. Consistent with Chang et al. (2012), 25 of the 26 models project an increase, with a multimodel mean increase of $52 \%$ (Table 1 ).
Spatial distribution of the projected increase is shown in Fig. 3c, which shows a band of increase extending from east of southern South America across the south Indian Ocean. There are also isolated areas of increase over the South Pacific. Unlike its climatology, where maximum activity is over the South Atlantic, maximum projected increase occurs in the south Indian Ocean near $90^{\circ} \mathrm{E}$.

The multimodel ensemble mean change over the South Pacific only shows very isolated spots of projected increase (Fig. 3c). However, when averaged over the area $30^{\circ}-60^{\circ} \mathrm{S}, 180^{\circ}-75^{\circ} \mathrm{W}, 24$ of the 26 models project increase in the frequency of extreme cyclones, again indicating an overall increase in extreme cyclone activity even though the spatial pattern of increase may not be robust.

\section{2) EXTREME VORTICITY CYCLONES}

Based on ERA-Interim, there are, on average, about 5.3 cyclones per winter month with $850-\mathrm{hPa}$ filtered vorticity perturbation amplitude exceeding $1.1 \times 10^{-4} \mathrm{~s}^{-1}$ (Table 1). The spatial distribution (Fig. 3d) differs somewhat from the distribution of extreme SLP cyclones, especially over the Pacific, where extreme cyclones in terms of vorticity are located about $20^{\circ}$ latitude equatorward of extreme SLP cyclones. CMIP5 simulations (Fig. 3e) also reflect this difference but tend to overestimate the number of cyclones close to Antarctica near the Weddell and Ross Seas. CMIP5 models, on average, underestimate the number of these cyclones by about $15 \%$ (Table 1 ).

Of the 26 models, 23 project an increase in the number of these cyclones (Fig. 2d), with a multimodel mean projected increase of about $29 \%$. The spatial distribution of the projected increase (Fig. 3f) is very similar to the projected increase in extreme SLP cyclones (areaweighted spatial anomaly correlation ${ }^{2}$ of 0.87 between $30^{\circ}$ and $60^{\circ} \mathrm{S}$ ), despite the differences in climatological distributions. Maximum increase is projected in the south Indian Ocean near $75^{\circ} \mathrm{E}$. The increase in the South Atlantic and south Indian Oceans largely follows the climatological storm track, but the increase over the Pacific occurs at a higher latitude than the climatological maximum over the basin. The multimodel mean projection also indicates decrease near the Weddell and Ross Seas, but again these decreases are mainly due to the two MRI models. Note that, over these regions, there are actually more models projecting increase than decrease.

\footnotetext{
${ }^{2}$ Note that we have also computed spatial pattern correlations for $30^{\circ}-70^{\circ} \mathrm{S}$, and the results are very similar in all cases.
} 


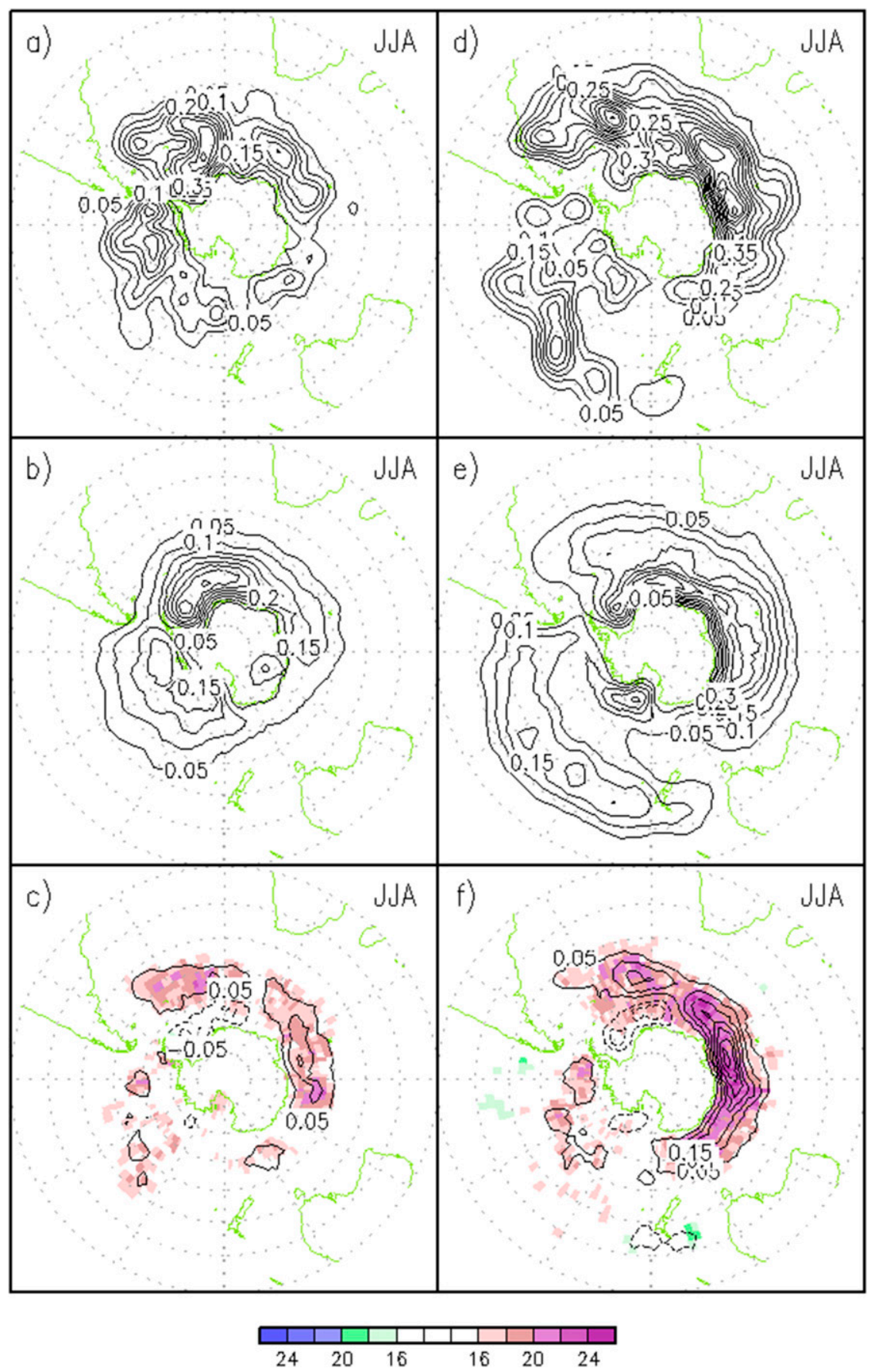

FIG. 3. (a)-(c) As in Fig. 1, but for frequency of extreme SLP cyclones with SLP perturbations $>$ $40 \mathrm{hPa}$. (d)-(f) As in Fig. 1, but for frequency of extreme cyclones in terms of 850-hPa vorticity (vorticity perturbation $>11 \times 10^{-5} \mathrm{~s}^{-1}$ ). The contour interval in all panels is $0.05 \%$. The ERAInterim climatologies shown in (a) and (d) have been smoothed using a 9-point $(3 \times 3)$ spatial filter.

\section{3) CYCLONES WITH STRONG WINDS}

About 5 cyclones per winter month have maximum wind at $850 \mathrm{hPa}$ surpassing $45 \mathrm{~m} \mathrm{~s}^{-1}$ within $555 \mathrm{~km}$ of their centers based on ERA-Interim data (Table 1). As expected, the spatial distribution of such cyclones (Fig. 4a) resembles a smoothed version of the spatial distribution of the frequency of extreme 850-hPa winds (Fig. 1d), with a band spiraling poleward from the western South Atlantic across the Indian Ocean into the 


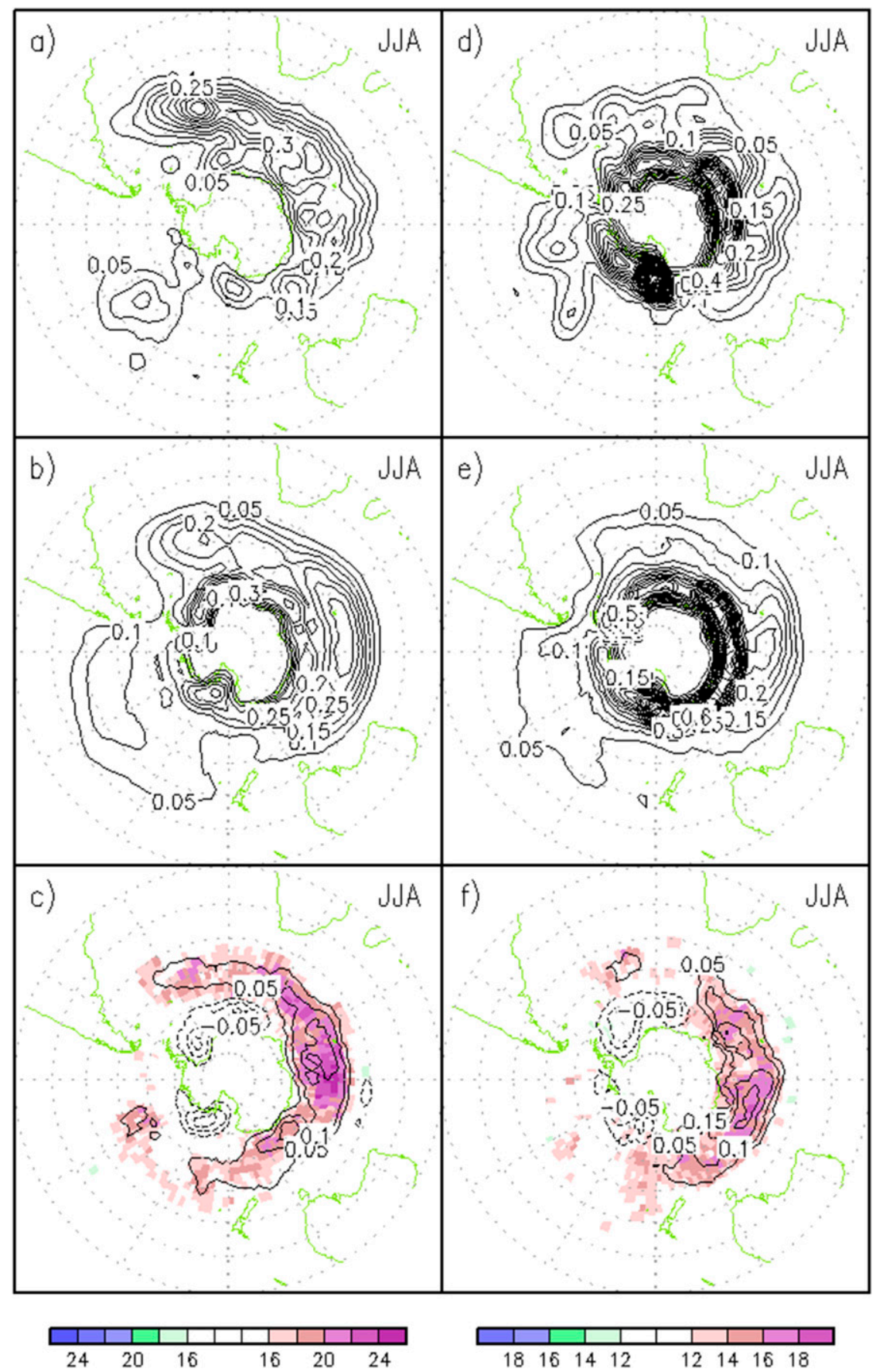

FIG. 4. (a)-(c) As in Fig. 1, but for frequency of cyclones with extreme 850 -hPa winds $\left(>45 \mathrm{~m} \mathrm{~s}^{-1}\right)$. (d)-(f) As in Fig. 1, but for frequency of cyclones with extreme near-surface winds (equivalent to a top-5 cyclone in a JJA month). Contour interval in all panels is $0.05 \%$. The ERA-Interim climatologies shown in (a) and (d) have been smoothed using a 9-point $(3 \times 3)$ spatial filter.

Pacific south of New Zealand, hugging the coast of Antarctica much of the way. There is a secondary region over the South Pacific near $130^{\circ} \mathrm{E}$. CMIP5 models simulate a somewhat similar distribution (Fig. 4b) but seem to overestimate the frequency of such cyclones close to the Antarctic coast as well as over much of the Pacific and underestimate the frequency over the South Atlantic.

Most CMIP5 models (23 out of 26) project an increase in the number of these cyclones under the RCP8.5 
scenario (Fig. 2e), with a multimodel mean increase of $46 \%$. Not surprisingly, the pattern of the projected change (Fig. 4c) resembles that of the projected change in the frequency of 850-hPa extreme winds (Fig. 1f). This pattern is also similar to those of projected changes in the frequency of extreme SLP (Fig. 3c; pattern correlation 0.81 between $30^{\circ}$ and $60^{\circ} \mathrm{S}$ ) and vorticity (Fig. 3f; pattern correlation 0.83) cyclones. Again, the projected decrease near the Antarctic coast in the Western Hemisphere is dominated by the two MRI models and is not robust across the ensemble.

Finally, we examine cyclones with extreme nearsurface winds within $555 \mathrm{~km}$ of their centers. As discussed in section 2, since CMIP5 models do not provide 6-hourly $10-\mathrm{m}$ winds, we use 6-hourly winds from the lowest model level (Table S2) provided by 19 of the 26 models. Since the height of the lowest model level varies from $10 \mathrm{~m}$ to about $60 \mathrm{~m}$ above the surface, using a fixed threshold for extreme wind speed is not justified, and hence we have used a different threshold for each model such that, on average, about 5 cyclone tracks in each winter month have winds exceeding this threshold between $30^{\circ}$ and $60^{\circ} \mathrm{S}$. The threshold used for each model is listed in Table S4. Note that projected changes in other cyclone statistics based on the 19 models with nearsurface winds are not statistically different from those based on the 7 remaining models; thus, it is meaningful to compare the projections based on these different ensembles.

For ERA-Interim wind data at $1.5^{\circ} \times 1.5^{\circ}$ resolution, the threshold is $26.0 \mathrm{~m} \mathrm{~s}^{-1}$, within the storm force category of the Beaufort scale $\left(>24.5 \mathrm{~m} \mathrm{~s}^{-1}\right)$. The spatial distribution of cyclones having such winds is displayed in Fig. 4d. This pattern differs quite a bit from the distribution of the other types of extreme cyclones, in that the maxima occur right along the coast of Antarctica, probably related to enhanced winds under the influence of the steep orography of Antarctica (Parish and Cassano 2003). This is why we have focused on examining the projected change between $30^{\circ}$ and $60^{\circ} \mathrm{S}$ in order to avoid the complications related to the interactions between cyclones and the steep orography, which may not be well resolved by CMIP5 models.

For CMIP5 models, the threshold (Table S4) ranges from $24.0 \mathrm{~m} \mathrm{~s}^{-1}$ for ACCESS1.3 (at $10 \mathrm{~m}$ ) to $42.5 \mathrm{~m} \mathrm{~s}^{-1}$ for MRI-CGCM3 (at a sigma level of 0.995, or around $40 \mathrm{~m}$ ). The spatial pattern of the climatology is simulated reasonably well (Fig. 4e). Of the 19 models, 17 project an increase in the number of these cyclones (Fig. 2f), with a multimodel mean increase of $19 \%$ (Table 1). The pattern of projected change (Fig. 4f) is very similar to that for change in cyclones with extreme $850-\mathrm{hPa}$ winds (Fig. 4c), with a pattern correlation of 0.89 . The main differences are less increase found in the South Atlantic and eastern South Pacific, with the main increase occurring over a band extending from south of South Africa to south of New Zealand.

Overall, results based on the four different definitions of extreme cyclones are very consistent, with over $88 \%$ of CMIP5 models projecting increase in the number of these cyclones, and with the spatial patterns of projected change also consistent between the different definitions despite large differences in the climatologies. A band of increase is projected to extend from the South Atlantic across the south Indian Ocean into the South Pacific, with maximum increase projected over the south Indian Ocean around $90^{\circ} \mathrm{E}$ and $45^{\circ}-60^{\circ} \mathrm{S}$.

\section{Results for other seasons}

The climatologies for $\mathrm{SH}$ spring [September-November (SON)], summer [December-February (DJF)], and fall [March-May (MAM)], based on ERA-Interim data, for all six quantities discussed in section 3, are shown in Figs. S2-S4 of the supplemental material for reference. Note that we have used the same thresholds to define extreme wind and extreme cyclones for all four seasons. There are fewer such cyclones during spring and fall and substantially fewer during SH summer (Table 1). Also note the contrast between the seasonal cycle in the number of extreme cyclones based on vorticity (5.3 in winter and 2.78 in summer) and those based on extreme $850-\mathrm{hPa}$ wind (4.95 in winter and 1.4 in summer) or extreme SLP (2.62 in winter and 0.6 in summer). Summer cyclones tend to be relatively stronger in terms of vorticity than in terms of other parameters. This is consistent with the results of Penny et al. (2010), who showed that, in the more extreme case, Northern Hemisphere Pacific cyclones defined by $300-\mathrm{hPa}$ vorticity maxima are stronger in summer than in winter because of the smaller spatial scale of summer cyclones.

Projected changes based on CMIP5 models are displayed in Figs. 5-7 and summarized in Table 1. Overall, CMIP5 models project statistically significant increase in the number of all four types of extreme cyclones (Table 1). Projected percentage increases in spring and summer are generally comparable to those for winter. In fall, projected increases in extreme vorticity cyclones as well as cyclones with extreme surface wind are less than those projected for the other seasons.

As for the spatial patterns of projected changes, ECApp (Figs. 5a-c) shows significant increase over all seasons in the SH mid-to-high latitudes and significant (in terms of model agreement) but very small decrease in the subtropics, highlighting the projected poleward shift and intensification of the near-surface SH storm 


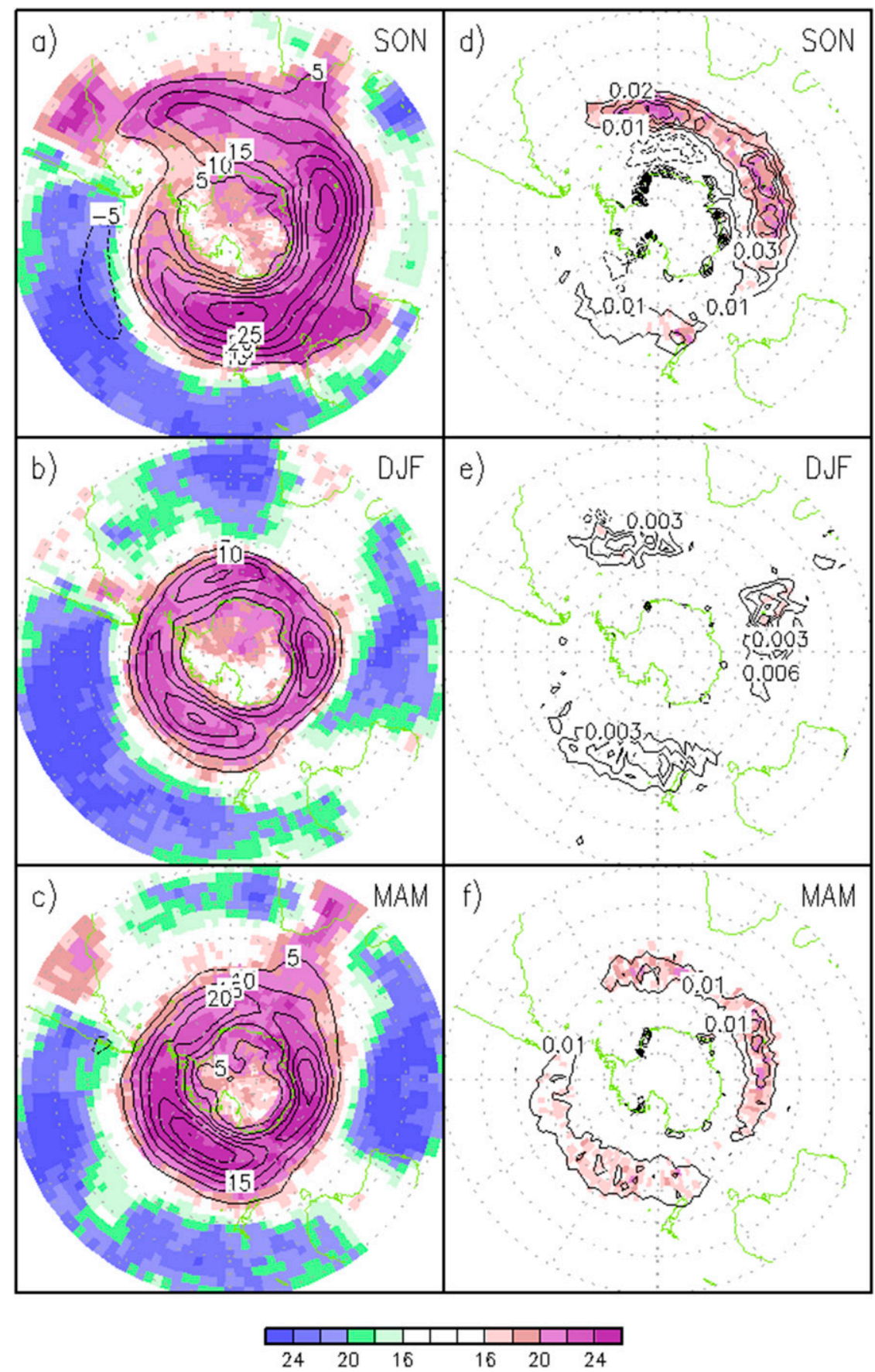

FIG. 5. CMIP5 multimodel ensemble mean projected change for ECApp (contour interval $5 \mathrm{hPa}^{2}$ ) for (a) spring (SON); (b) summer (DJF); and (c) fall (MAM). (d)-(f) As in (a)-(c), but for the frequency of extreme $850-\mathrm{hPa}$ wind [ $>45 \mathrm{~m} \mathrm{~s}^{-1}$; contour interval $0.01 \%$ in (d) and (f) and $0.003 \%$ in (e)]. The color shades in all panels show the number of models projecting the same sign of change at each grid box.

track in terms of variance statistics found in many previous studies (e.g., Yin 2005; Chang et al. 2012).

For frequency of extreme wind at $850 \mathrm{hPa}$, the increase in spring (Fig. 5d) is rather similar to that in winter (Fig. 1f). For summer and fall, the multimodel ensemble also projects increase, but model agreement on the spatial location of increase is not as strong, especially in summer (Fig. 5e). That is likely because these events are very rare in summer (see Fig. S4d), and thus the spatial statistics are very noisy. Nevertheless, the 


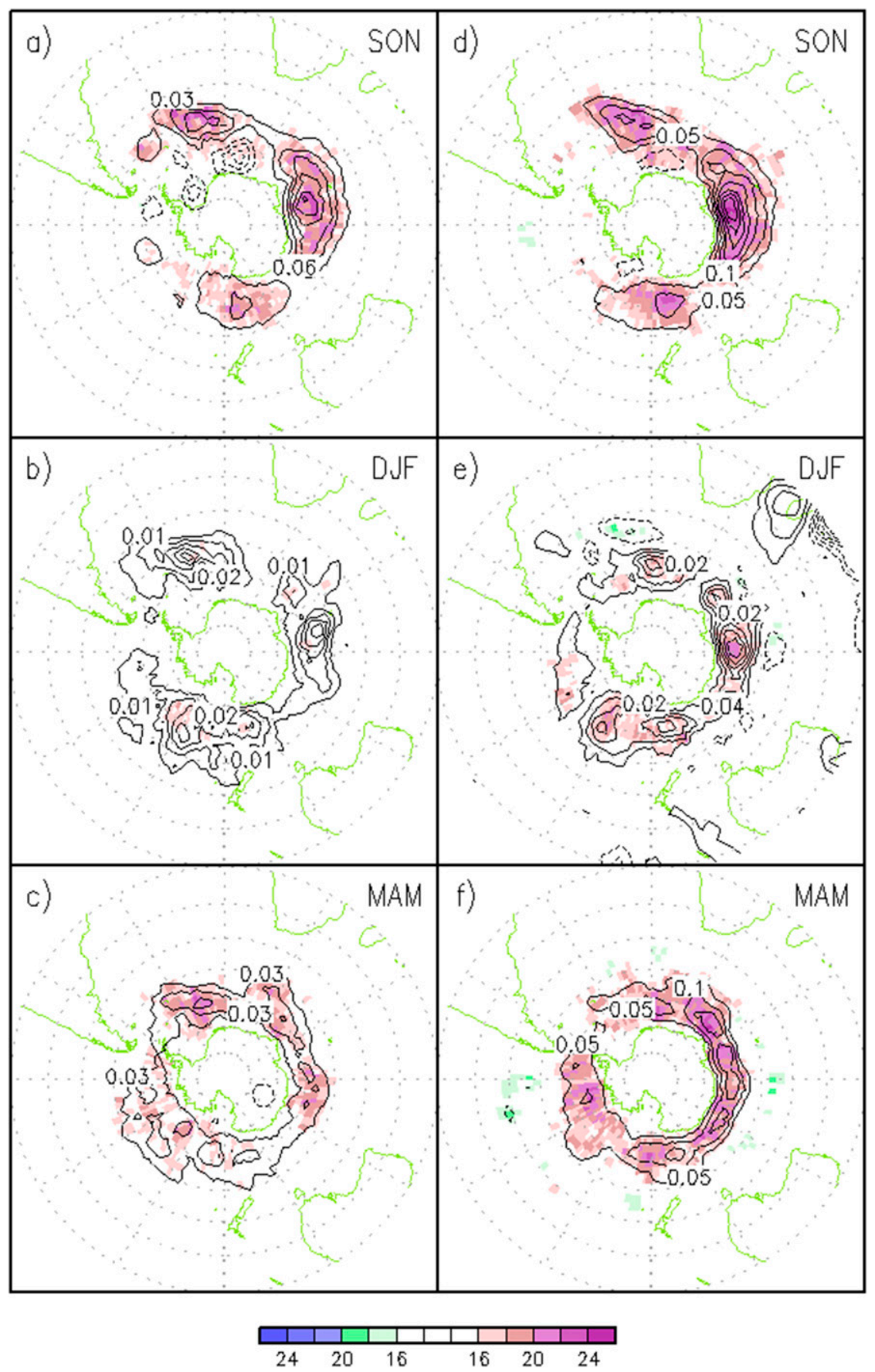

FIG. 6. As in Fig. 5, but for (a)-(c) frequency of extreme SLP cyclones with SLP perturbations $>40 \mathrm{hPa}$ [contour interval $0.03 \%$ in (a) and (c), $0.01 \%$ in (b)]. (d)-(f) As in (a)-(c), but for extreme cyclones with $850-\mathrm{hPa}$ vorticity perturbation $>11 \times 10^{-5} \mathrm{~s}^{-1}$ [contour intervals $0.05 \%$ in (d) and (f), $0.02 \%$ in (e)].

three regions of projected increase correspond rather well with the three maxima for ECApp (Fig. 5b), except that they are located at lower latitudes. Averaged over $30^{\circ}-60^{\circ} \mathrm{S}, 25$ models project increase in spring, 24 in summer, and 25 in fall.
Projected changes in the frequency of extreme SLP and vorticity cyclones are shown in Fig. 6. Again, model agreement is strongest in spring and worst in summer. Figure 6 shows that the projected patterns of change are very similar between these two types of cyclones, with 


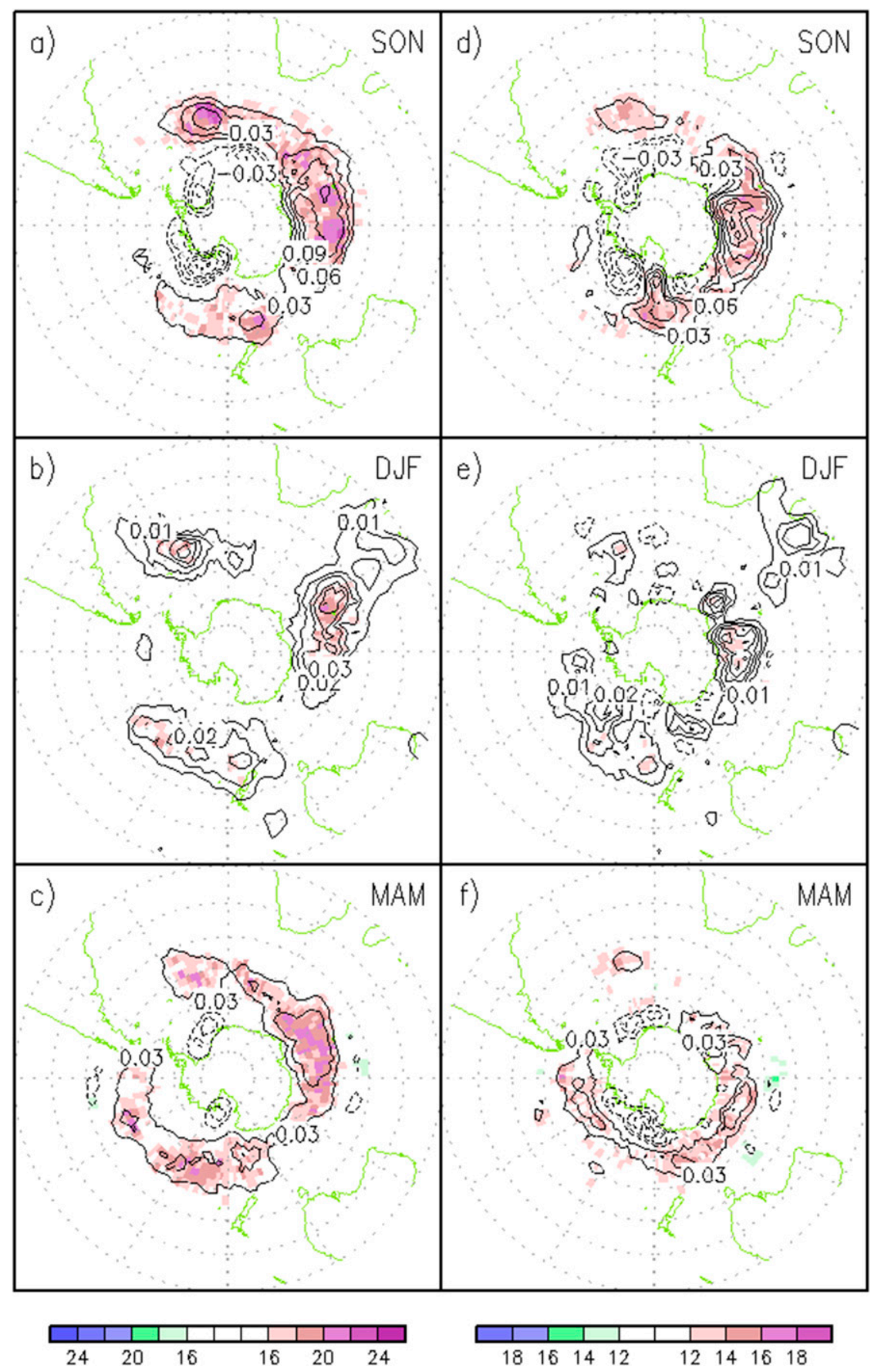

FIG. 7. As in Fig. 5, but for (a)-(c) frequency of cyclones with extreme $850-\mathrm{hPa}$ winds [ $>45 \mathrm{~m} \mathrm{~s}^{-1}$; contour interval $0.03 \%$ for (a) and (c), $0.01 \%$ in (b)]; and (d)-(f) frequency of cyclones with extreme near-surface winds [equivalent to top-5 cyclone in a JJA month; contour interval $0.03 \%$ for (d) and (f), $0.01 \%$ in (e)].

slightly larger increases projected in the frequency of extreme vorticity cyclones as a result of their higher climatological frequency (see Table 1).

Projected change in the frequency of cyclones with extreme winds is shown in Fig. 7. Comparing Figs. 7a-c to Fig. 6, projected increases in the frequency of cyclones with extreme $850-\mathrm{hPa}$ winds tend to occur slightly equatorward of projected increases in cyclones with extreme vorticity or extreme SLP, but the patterns of increase are very similar. As for cyclones with 
extreme surface wind, the projected increase in spring (Fig. 7d) appears to be most robust, with those in summer (Fig. 7e) and fall (Fig. 7f) projected to be more noisy and limited in extent. Nevertheless, when averaged over $30^{\circ}-60^{\circ} \mathrm{S}, 17$ of 19 models project increase in summer, 15 in fall, and 16 in spring, showing overall model agreement in projected overall increase over the midlatitude $\mathrm{SH}$.

\section{Discussion}

\section{a. Sensitivity to definition of extreme cyclones}

In the discussions above in sections 3 and 4, we largely showed results for extreme cyclones based on the same threshold, but for surface winds. Here, we briefly explore whether projected changes are sensitive to the exact definition of extreme cyclones.

First, we examine extreme cyclones based on $850-\mathrm{hPa}$ vorticity. Projected percentage change based on the same threshold of $1.1 \times 10^{-4} \mathrm{~s}^{-1}$ for each model has been shown in Fig. 3f. An alternative definition is based on a vorticity threshold corresponding to an average of 5 cyclones per winter month. The threshold for each model is listed in Table S3. The threshold ranges from 0.96 to $1.27 \times 10^{-4} \mathrm{~s}^{-1}$. Projected percentage change for each model is shown in Fig. 8a. Of the 27 models, 26 project an increase. While there are some quantitative differences between the projections based on these two definitions, model-to-model correlation of the projected percentage change is 0.80 . A third definition is based on a vorticity threshold corresponding to an average of 1 cyclone per winter month (Table S3). The results for this more extreme definition are shown in Fig. 8d. Again, 26 of the 27 models project an increase, and the model-to-model correlation between projections based on this definition and the constant threshold is 0.88 , while the correlation with results based on the top- 5 threshold is 0.86 .

Similar results are found for extreme cyclones based on maximum $850-\mathrm{hPa}$ wind near the cyclone center corresponding to the top-5 and top- 1 cyclones per winter month (Table S4; Figs. $8 \mathrm{~b}$ and $8 \mathrm{e}$ ), as well as maximum near-surface wind near the cyclone center corresponding to the top-5 and top-1 cyclones (Table S4; Figs. 8c and 8f). For all cases, projected percentage increase is highest for extreme cyclones defined by the top-1 category (Tables S5 and S6 in the supplemental material). The spatial patterns for the climatology and projected changes for top-5 cyclones based on SLP, 850-hPa vorticity, and 850-hPa winds are shown in Fig. $\mathrm{S} 5$ of the supplemental material. These results show that our conclusion that CMIP5 models project a significant increase in the number of extreme cyclones over $\mathrm{SH}$ is not sensitive to the definition of extreme cyclones.

\section{b. Consistency between different kinds of extreme cyclones}

In the previous sections, we have examined CMIP5 projected changes of $\mathrm{SH}$ extreme cyclone activity based on different definitions of cyclones and found overall agreement in that nearly all models project an increase in extreme cyclones regardless of the definition and that the spatial distributions of the multimodel mean projected increase are all rather similar. Here, we would like to further quantify the consistency between the different definitions by examining the model-to-model correlation between the projected changes (all averaged over $30^{\circ}-60^{\circ} \mathrm{S}$ ) based on the different definitions.

Correlations for $\mathrm{SH}$ winter, for 5 of the 6 quantities discussed in section 3, are shown in the top four rows of Table 2. Highest consistency (with a correlation of 0.79 ) is found between the projected percentage changes in ECApp and the frequency of extreme cyclones defined based on SLP perturbation using a threshold equivalent to the top-5 cyclones in an average winter month during the historical period. That is, when a model projects a large (small) percentage change in ECApp, it is very likely that it also projects a large (small) percentage change in the frequency of extreme SLP cyclones. Figure 9a shows a scatterplot between model-projected changes in these two quantities for all four seasons (separated by different colored symbols), showing positive correlation in all four seasons. However, results of the four seasons do not seem to lie on the same regression line, with the same percentage increase in ECApp associated with larger increase in the frequency of extreme SLP cyclones during summer. Note that most points lie above the one-to-one line. This is likely because ECApp variability is dominated by moderate rather than extreme cyclones. Since these extreme events are rarest in summer, it is not surprising that the relative change of extreme cyclones in summer with respect to ECApp should be largest. Averaged over the four seasons, the correlation of 0.61 (see Table 3) between projected changes based on these two quantities is still relatively high.

Projected changes in the frequency of extreme cyclones defined based on SLP and $850-\mathrm{hPa}$ vorticity minima are also highly consistent, with a correlation of 0.70 for the $\mathrm{SH}$ winter, and 0.63 when averaged over the four seasons. For these two quantities, results from all four seasons seem to lie more or less on the one-to-one line (Fig. 8c). Similarly, projected changes in the frequency of extreme SLP cyclones and cyclones with extreme $850-\mathrm{hPa}$ winds are also highly consistent, with 
a) Individual model \% change in \# vorticity cyclones (Top 5 JJA 30-60S)

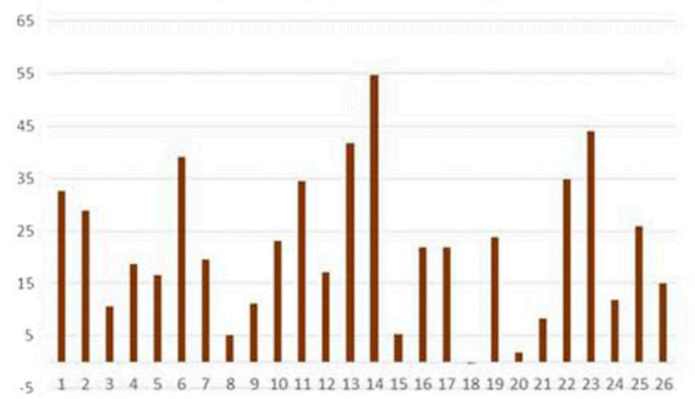

b) Individual model \% change in \# extreme 850 wind cyclones (Top $5 \mathrm{JJA}$ 30-60S)

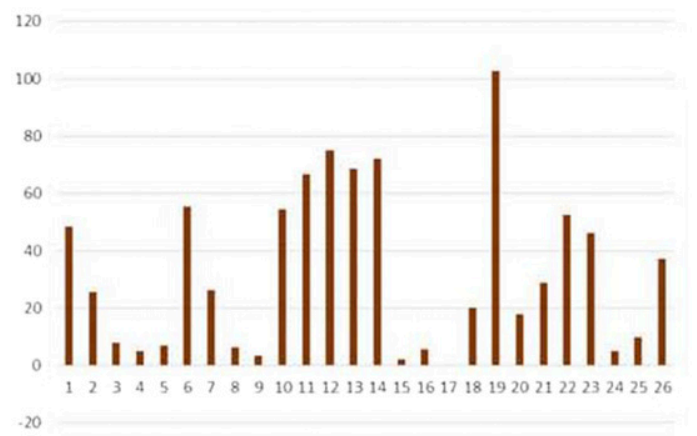
$-20$

c) Individual model \% change in \# extreme near surface wind cyclones (Top $5 \mathrm{JJA}$ 30-60S)

80

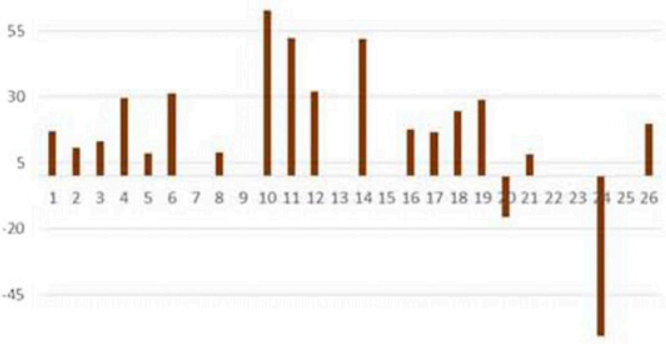

d) Individual model \% change in \# vorticity cyclones (Top 1 JJA 30-60S)

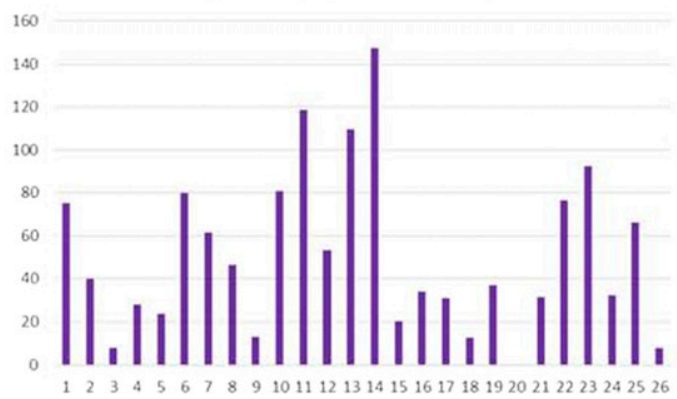

e) Individual model \% change in \# extreme 850 wind cyclones (Top $1 \mathrm{JJA}$ 30-60S)

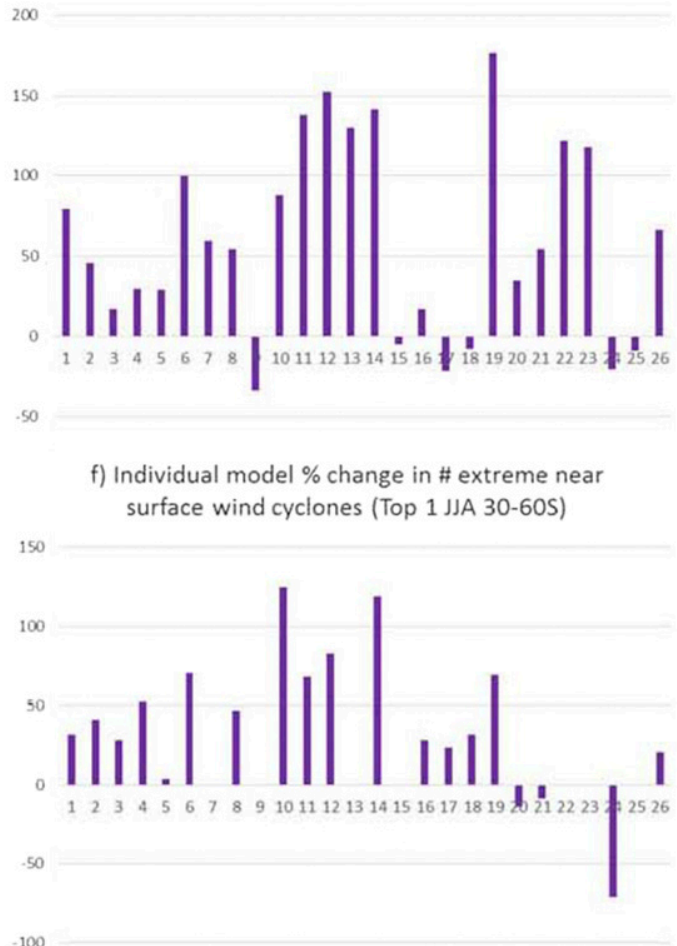

FIG. 8. Projected percentage changes in the number of extreme cyclones in JJA, defined based on a threshold equivalent to a top-5 cyclone per month in JJA for each model for: (a) 850-hPa vorticity perturbations, (b) 850-hPa winds, and (c) near-surface winds. (d)-(f) As in (a)-(c), but for a threshold equivalent to a top-1 cyclone per month in JJA.

correlation of 0.69 for JJA, and 0.58 when averaged over the four seasons. Figure $8 \mathrm{~b}$ shows that again results for all four seasons seem to lie on the same regression line.

Overall, correlations are rather high for winter and lower for the other seasons, especially for summer. This may be because these extreme cyclones are most frequent in winter and least so in summer; hence, the statistics are noisier in summer, giving rise to poorer agreement.

\section{c. Consistency with mean flow change}

Figure 2 highlights significant model-to-model differences in the magnitude of projected changes in extreme cyclone statistics. Can we understand these differences? O'Gorman (2010) showed that projected changes in hemispheric averaged EKE found in CMIP3 model simulations are proportional to projected changes in MAPE. Hence, changes in MAPE are computed for each pair of historical and future model simulations. Here, the expression of MAPE formulated by Orlanski and Katzfey (1991), integrated over $30^{\circ}-60^{\circ} \mathrm{S}$ and from 850 to $300 \mathrm{hPa}$, is used. MAPE is based entirely on the temperature distribution, increasing with larger temperature gradient and weaker static stability. Apart from MAPE, we have also examined 
TABLE 2. Model-to-model correlation between projected JJA percentage changes in the following: number of extreme cyclones based on top 5 per JJA month (i) in terms of SLP perturbation, (ii) in terms of vorticity perturbation, (iii) in terms of 850-hPa maximum wind, and (iv) in terms of near-surface maximum wind; (v) ECApp; (vi) MAPE; and (vii) zonal wind at $850 \mathrm{hPa}$ (um850).

\begin{tabular}{|c|c|c|c|c|c|c|}
\hline JJA & SLP top 5 & Vorticity top 5 & $850-\mathrm{hPa}$ wind top 5 & Surface wind top 5 & ECApp & MAPE \\
\hline Vorticity top 5 & 0.70 & & & & & \\
\hline $850-\mathrm{hPa}$ wind top 5 & 0.69 & 0.60 & & & & \\
\hline Surface wind top 5 & 0.62 & 0.52 & 0.56 & & & \\
\hline ECApp & 0.79 & 0.31 & 0.55 & 0.50 & & \\
\hline MAPE & 0.58 & 0.28 & 0.09 & 0.16 & 0.73 & \\
\hline um850 & 0.62 & 0.07 & 0.32 & 0.24 & 0.86 & 0.72 \\
\hline
\end{tabular}

changes in the zonal mean zonal wind at the 850-hPa level to represent an alternative measure of mean flow change. Note that the change in zonal mean zonal wind is largely barotropic between 925 and $500 \mathrm{hPa}$ [not shown, but see previous studies, such as Yin (2005)], suggesting that this change represents change in the eddy-driven jet and is largely a response to changes in eddy momentum flux convergence. Changes in $850-\mathrm{hPa}$ zonal wind are averaged over $40^{\circ}-60^{\circ} \mathrm{S}$ where the change is largest.

Correlations between model-projected changes in MAPE and 850-hPa zonal wind with cyclone statistics are shown in the last two rows of Table 2 for $\mathrm{SH}$ winter and the last two rows of Table 3 for averages over all four seasons. Consistent with O'Gorman (2010), changes in MAPE are relatively well correlated with changes in ECApp, which is an eddy variance statistics similar to EKE. Figure 9d shows a scatterplot between projected changes in MAPE and ECApp, showing rather tight relationships for all four seasons. The correlation between changes in MAPE and the number of extreme SLP cyclones is also moderately high in winter but is low in the other seasons. Results presented in Tables 2 and 3 show that changes in MAPE (as well as $850-\mathrm{hPa}$ zonal wind) are not well correlated to changes in the number of extreme cyclones defined based on $850-\mathrm{hPa}$ vorticity, $850-\mathrm{hPa}$ maximum wind, or near-surface maximum wind. Thus, while projected change in MAPE can, to a certain extent, "explain" the projected change in variance statistics, it has little utility in explaining change in the frequency of extreme cyclones, especially extreme cyclones defined in terms of maximum winds.

Tables 2 and 3 also show that projected changes in 850-hPa zonal wind are highly correlated with projected changes in ECApp. This is likely due to the aforementioned fact that changes in $850-\mathrm{hPa}$ zonal wind likely represents a response to changes in eddy momentum fluxes, which should be highly correlated with changes in ECApp. Note that projected changes in $850-$ hPa zonal wind are also not well correlated with changes in the number of extreme cyclones. These results suggest that, while changes in the frequency of extreme cyclones are moderately correlated with changes in ECApp, they are not significantly correlated with changes in MAPE (Table 3). Thus, finding a mean flow metric that can quantitatively explain the changes in the statistics of extreme cyclones remains a challenge.

\section{d. Sensitivity to model resolution}

In the past, many studies have found that climate model simulation of storm-track activity is highly dependent on model resolution, with low-resolution models simulating storm-track amplitudes that are systematically too low (e.g., Boville 1991). Chang et al. (2013) found that there is a moderate negative correlation between model grid spacing and storm-track amplitudes in 17 CMIP3 models. Here, we briefly examine whether CMIP5 projections show any strong dependence on model resolution.

The horizontal resolution of each model simulation is tabulated in Table S2. We have correlated the model gridbox size (equal to the product of the latitude and longitude grid spacing) with the climatology and projected changes in all the quantities we have discussed, including both Eulerian and Lagrangian cyclone statistics, and have not found any correlation that is significant even at the $10 \%$ level. The climatology and projected changes of extreme cyclones based on SLP, vorticity, and $850-\mathrm{hPa}$ winds, for 10 high-resolution and 10 low-resolution models, are shown in Figs. S6 and S7 of the supplemental material, respectively. We can see that the projected changes from these two sets of models are very similar. Thus, we conclude that projected storm-track changes in CMIP5 simulations are not very sensitive to model resolution. This is consistent with the results of Bengtsson et al. (2009).

\section{Summary and conclusions}

In this study, projected changes in extreme cyclones in the SH based on 26 CMIP5 models have been computed. Multiple definitions of extreme cyclones have been examined, including intensity exceeding constant thresholds of SLP perturbations, 850-hPa vorticity, and 850-hPa 
a) \# SLP cyclones vs pp

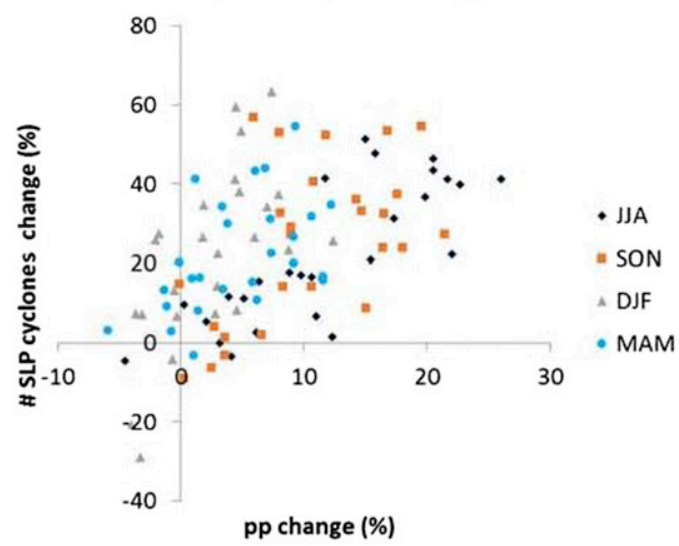

b) \# 850 strong wind vs SLP cyclones

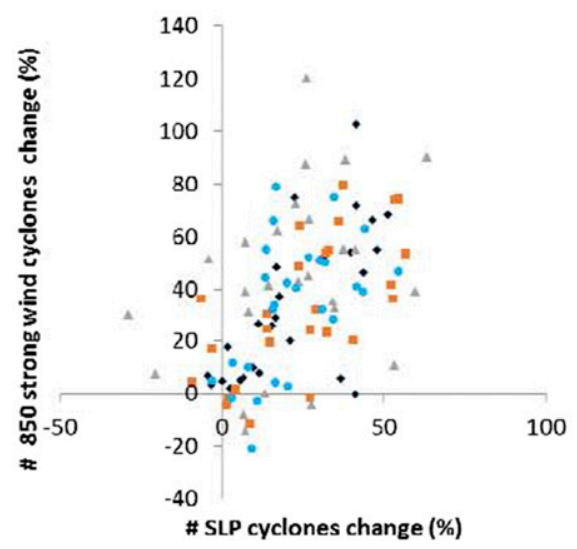

c) \# 850 vorticity vs SLP cyclones
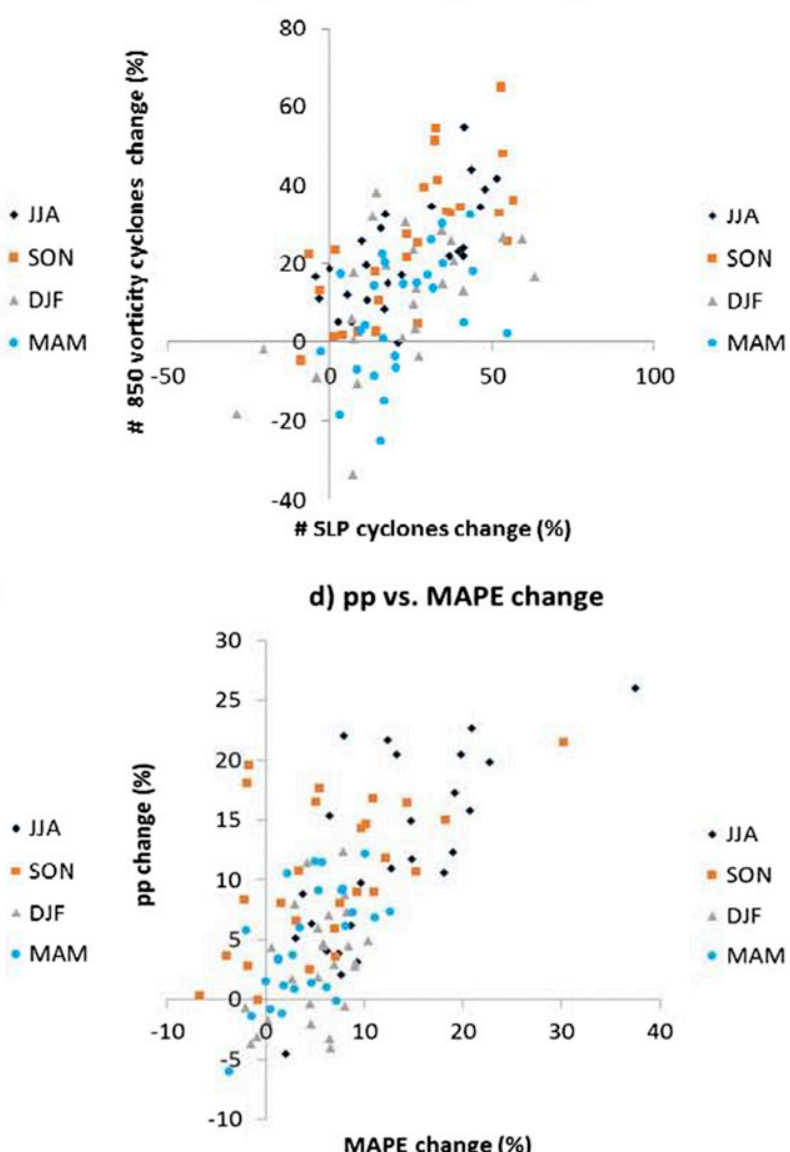

d) pp vs. MAPE change

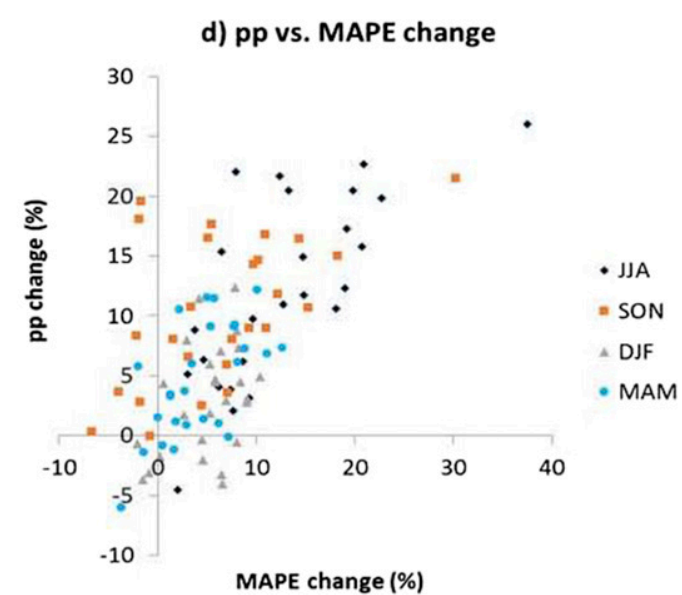

FIG. 9. Scatterplots between CMIP5 model-projected percentage changes in (a) ECApp and number of extreme SLP cyclones; (b) number of extreme SLP cyclones and number of extreme cyclones in terms of 850-hPa winds; (c) number of extreme SLP cyclones and extreme cyclones in terms of 850-hPa vorticity; and (d) ECApp and MAPE. All quantities are computed in the $30^{\circ}-60^{\circ} \mathrm{S}$ band.

winds, as well as variable thresholds corresponding to a top- 5 or top- 1 cyclone in these three parameters and the near-surface winds for each model. Results presented in this study show that, under the RCP8.5 pathway, CMIP5 models project a significant increase in the frequency of extreme cyclones between 1980-99 and 2081-2100 in all four seasons regardless of the definition, with over $88 \%$ of the models projecting an increase. The projected spatial change patterns are also consistent between the different definitions of extreme cyclones, with the largest increase projected between $45^{\circ}$ and $60^{\circ} \mathrm{S}$, extending from the South Atlantic across the south Indian Ocean into the South Pacific, with the maximum located over the south Indian Ocean.

Overall, our results are consistent with those of Chang et al. (2012), who showed that CMIP5 models project

TABLE 3. As in Table 2, but the correlations have been averaged over all four seasons.

\begin{tabular}{|c|c|c|c|c|c|c|}
\hline Averaged over all four seasons & SLP top 5 & Vorticity top 5 & $850-\mathrm{hPa}$ wind top 5 & Surface wind top 5 & ECApp & MAPE \\
\hline Vorticity top 5 & 0.63 & & & & & \\
\hline $850-\mathrm{hPa}$ wind top 5 & 0.58 & 0.51 & & & & \\
\hline Surface wind top 5 & 0.35 & 0.32 & 0.51 & & & \\
\hline ECApp & 0.61 & 0.40 & 0.53 & 0.20 & & \\
\hline MAPE & 0.31 & 0.27 & 0.03 & 0.01 & 0.55 & \\
\hline um850 & 0.41 & 0.02 & 0.32 & 0.01 & 0.68 & 0.49 \\
\hline
\end{tabular}


significant increase in the frequency of strong cyclones defined in terms of SLP perturbations. Our results are moderately consistent with those of Grieger et al. (2014), who showed that an increase in the number of strong cyclones (top 5 percentile in terms of Laplacian in SLP) is found in most of the model simulations they examined, but they found much more modest changes of between $-12.8 \%$ and $23.7 \%$, with an ensemble mean (from 9 simulations) of only $+7.5 \%$. Here, our results show that, for similarly extreme cyclones, CMIP5 models project much larger changes. The difference is likely due to the difference in scenarios used (their simulations used the SRES A1B scenario, while here we examined the higher-emission RCP8.5 simulations) as well as different models included in the ensembles.

As discussed above, Bengtsson et al. (2009) found no significant increase in extreme winds (at $925 \mathrm{hPa}$ ) and $850-\mathrm{hPa}$ vorticity near cyclones anywhere. However, Bengtsson et al. (2009) only examined simulations based on one model (ECHAM5). Our results indicate that, out of the 26 CMIP5 models, a few project little changes or even a decrease in the number of extreme cyclones; thus, it is likely that the model used by Bengtsson et al. (2009) has similar behavior to one of these models that project small changes. Given the large spread found in the different model simulations, it is clear that general conclusions cannot be drawn based on simulations using only one (or even a few) model. It is of interest to note that the two MPI models (numbers 23 and 24), which use a newer version of the ECHAM model (ECHAM6), both project significant increase in ECApp, the frequency of extreme 850-hPa winds, as well as the number of extreme cyclones (see Fig. 2). Finally, it was stated in the IPCC AR5 (Christensen et al. 2013,p. 1252) that "the CMIP5 model projections show little evidence of change in the intensity of winds associated with ETCs." Our results show that CMIP5 models clearly project significant increase in the frequency of cyclones with extreme wind in the SH. It should be noted that there are indications that the number of intense cyclones over the SH has increased over the past decades (Wang et al. 2016). However, trends derived from different reanalysis datasets are quite different, and it is not clear how the large changes in the quantity and quality of observations may have impacted these trends.

Our results indicate that, while model-projected changes in the frequency of extreme cyclones correlate moderately well with changes in Eulerian indices such as ECApp, which correlate significantly with changes in MAPE, projected changes in the frequency of extreme cyclones are not significantly correlated with those in MAPE. Thus, there is still a challenge in finding mean flow metrics that can quantitatively explain the changes in extreme cyclone frequency. In addition, our results indicate that CMIP5 model simulations show no indications that projected changes in extreme cyclone statistics are sensitive to model grid spacing. Nevertheless, the highest-resolution model included in our ensemble may still be unable to well resolve the impact of diabatic heating on cyclone development (Willison et al. 2013), and thus further examinations of climate simulations with grid spacing of $25 \mathrm{~km}$ or less are needed to resolve the issue of whether diabatic impacts on cyclone development may undergo significant changes in a warmer and moister climate.

In this study, projections based on the high-emission RCP8.5 pathway have been examined. For lower emission scenarios, Chang et al. (2012) showed that CMIP5projected change in variance statistics is roughly proportional to the projected temperature change, but it is not clear whether this result also applies to extreme events. It would be of interest to examine projections of lower-emission scenarios, especially since under these scenarios the effects of ozone recovery may largely cancel those of increasing greenhouse gas forcing during SH summer (Polvani et al. 2011).

Acknowledgments. The author would like to thank Kevin Hodges for providing the cyclone tracking code, Albert Yau for assistance in downloading some of the data, and the Earth System Grid and the climate modeling centers for providing the CMIP5 data. The author would also like to thank three anonymous reviewers for providing comments that help to clarify the manuscript. This research is supported by NSF Grant AGS-1261311 and NASA Grant NNX16AG32G.

\section{REFERENCES}

Alexander, L. V., S. F. B. Tett, and T. Jonsson, 2005: Recent observed changes in severe storms over the United Kingdom and Iceland. Geophys. Res. Lett., 32, L13704, doi:10.1029/ 2005 GL022371.

Ashley, W. S., and A. W. Black, 2008: Fatalities associated with nonconvective high-wind events in the United States. J. Appl. Meteor. Climatol., 47, 717-725, doi:10.1175/2007JAMC1689.1.

Barnes, E. A., N. W. Barnes, and L. M. Polvani, 2014: Delayed Southern Hemisphere climate change induced by stratospheric ozone recovery, as projected by the CMIP5 models. J. Climate, 27, 852-867, doi:10.1175/JCLI-D-13-00246.1.

Bengtsson, L., K. I. Hodges, and N. Keenlyside, 2009: Will extratropical storms intensify in a warmer climate? J. Climate, 22 , 2276-2301, doi:10.1175/2008JCLI2678.1.

Blackmon, M. L., 1976: A climatological spectral study of the $500 \mathrm{mb}$ geopotential height of the Northern Hemisphere. J. Atmos. Sci., 33, 1607-1623, doi:10.1175/1520-0469(1976)033<1607: ACSSOT $>2.0 . \mathrm{CO} ; 2$.

Boville, B. A., 1991: Sensitivity of simulated climate to model resolution. J. Climate, 4, 469-485, doi:10.1175/1520-0442(1991)004<0469: SOSCTM $>2.0 . \mathrm{CO} 2$. 
Catto, J. L., E. Madonna, H. Joos, I. Rudeva, and I. Simmonds, 2015: Global relationship between fronts and warm conveyor belts and the impact on extreme precipitation. J. Climate, $\mathbf{2 8}$, 8411-8429, doi:10.1175/JCLI-D-15-0171.1.

Chang, E. K. M., 2014: Impacts of background field removal on CMIP5 projected changes in Pacific winter cyclone activity. J. Geophys. Res. Atmos., 119, 4626-4639, doi:10.1002/ 2013JD020746.

sphere winter storm track intensity. J. Climate, 15, 642-658, doi:10.1175/1520-0442(2002)015<0642:IVINHW>2.0.CO;2.

—, Y. Guo, and X. Xia, 2012: CMIP5 multimodel ensemble projection of storm track change under global warming. J. Geophys. Res., 117, D23118, doi:10.1029/2012JD018578.

,,--- , and M. Zheng, 2013: Storm-track activity in IPCC AR4/CMIP3 model simulations. J. Climate, 26, 246-260, doi:10.1175/JCLI-D-11-00707.1.

, C. Zheng, P. Lanigan, A. M. W. Yau, and J. D. Neelin, 2015: Significant modulation of variability and projected change in California winter precipitation by extratropical cyclone activity. Geophys. Res. Lett., 42, 5983-5991, doi:10.1002/ 2015 GL064424.

Christensen, J., and Coauthors, 2013: Climate phenomena and their relevance for future regional climate change. Climate Change 2013: The Physical Science Basis, T. F. Stocker et al., Eds., Cambridge University Press, 1217-1308, doi:10.1017/ CBO9781107415324.028.

Colle, B. A., F. Buonaiuto, M. J. Bowman, R. E. Wilson, R. Flood, R. Hunter, A. Mintz, and D. Hill, 2008: New York City's vulnerability to coastal flooding. Bull. Amer. Meteor. Soc., 89, 829-841, doi:10.1175/2007BAMS2401.1.

—, Z. Zhang, K. A. Lombardo, E. K. M. Chang, P. Liu, and M. Zhang, 2013: Historical evaluation and future prediction of eastern North American and western Atlantic extratropical cyclones in the CMIP5 models during the cool season. J. Climate, 26, 6882-6903, doi:10.1175/JCLI-D-12-00498.1.

Collins, M., and Coauthors, 2013: Long-term climate change: Projections, commitments and irreversibility. Climate Change 2013: The Physical Science Basis, T. F. Stocker et al., Eds., Cambridge University Press, 1029-1136, doi:10.1017/ CBO9781107415324.024.

Dee, D. P., and Coauthors, 2011: The ERA-Interim reanalysis: Configuration and performance of the data assimilation system. Quart. J. Roy. Meteor. Soc., 137, 553-597, doi:10.1002/qj.828.

Feser, F., M. Barcikowska, O. Krueger, F. Schenk, R. Weisse, and L. Xia, 2015: Storminess over the North Atlantic and northwestern Europe-A review. Quart. J. Roy. Meteor. Soc., 141, 350-382, doi:10.1002/qj.2364.

Grieger, J., G. C. Leckebusch, M. G. Donat, M. Schuster, and U. Ulbrich, 2014: Southern Hemisphere winter cyclone activity under recent and future climate conditions in multi-model AOGCM simulations. Int. J. Climatol., 34, 34003416, doi:10.1002/joc.3917.

Hodges, K. I., 1999: Adaptive constraints for feature tracking. Mon. Wea. Rev., 127, 1362-1373, doi:10.1175/1520-0493(1999)127<1362: ACFFT $>2.0 . \mathrm{CO} ; 2$.

Hoskins, B. J., and K. I. Hodges, 2002: New perspectives on the Northern Hemisphere winter storm tracks. J. Atmos. Sci., 59, 1041-1061, doi:10.1175/1520-0469(2002)059<1041: NPOTNH $>2.0 . \mathrm{CO} ; 2$.

$\longrightarrow$, and - 2005: A new perspective on Southern Hemisphere storm tracks. J. Climate, 18, 4108-4129, doi:10.1175/JCLI3570.1.
Lambert, S. J., and J. C. Fyfe, 2006: Changes in winter cyclone frequencies and strengths simulated in enhanced greenhouse warming experiments: Results from the models participating in the IPCC diagnostic exercise. Climate Dyn., 26, 713-728, doi:10.1007/s00382-006-0110-3.

Lim, E.-P., and I. Simmonds, 2002: Explosive cyclone development in the Southern Hemisphere and a comparison with Northern Hemisphere events. Mon. Wea. Rev., 130, 2188-2209, doi:10.1175/ 1520-0493(2002)130<2188:ECDITS>2.0.CO;2.

$\longrightarrow$, and - 2009: Effects of tropospheric temperature change on the zonal mean circulation and $\mathrm{SH}$ winter extratropical cyclones. Climate Dyn., 33, 19-32, doi:10.1007/s00382-008-0444-0.

Lorenz, E. N., 1955: Available potential energy and the maintenance of the general circulation. Tellus, 7A, 157-167, doi:10.1111/ j.2153-3490.1955.tb01148.x.

Neu, U., and Coauthors, 2013: IMILAST: A community effort to intercompare extratropical cyclone detection and tracking algorithms. Bull. Amer. Meteor. Soc., 94, 529-547, doi:10.1175/ BAMS-D-11-00154.1.

O'Gorman, P. A., 2010: Understanding the varied response of the extratropical storm tracks to climate change. Proc. Natl. Acad. Sci. USA, 107, 19176-19 180, doi:10.1073/pnas.1011547107.

Orlanski, I., 2013: What controls recent changes in the circulation of the Southern Hemisphere: Polar stratospheric or equatorial surface temperatures? Atmos. Climate Sci., 3, 497-509.

_ - and J. Katzfey, 1991: The life cycle of a cyclone wave in the Southern Hemisphere. Part I: Eddy energy budget. J. Atmos. Sci., 48, 1972-1998, doi:10.1175/1520-0469(1991)048<1972: TLCOAC $>2.0$. CO; 2 .

Parish, T. R., and J. J. Cassano, 2003: The role of katabatic winds on the Antarctic surface wind regime. Mon. Wea. Rev., 131, 317-333, doi:10.1175/1520-0493(2003)131<0317:TROKWO>2.0.CO;2.

Peixoto, J. P., and A. H. Oort, 1992: Physics of Climate. American Institute of Physics, $520 \mathrm{pp}$.

Penny, S., G. H. Roe, and D. S. Battisti, 2010: The source of the midwinter suppression in storminess over the North Pacific. J. Climate, 23, 634-648, doi:10.1175/2009JCLI2904.1.

Pezza, A. B., I. Simmonds, and J. A. Renwick, 2007: Southern Hemisphere cyclones and anticyclones: Recent trends and links with decadal variability in the Pacific Ocean. Int. J. Climatol., 27, 1403-1419, doi:10.1002/joc.1477.

- H. A. Rashid, and I. Simmonds, 2012: Climate links and recent extremes in Antartic sea ice, high-latitude cyclones, southern annular mode and ENSO. Climate Dyn., 38, 57-73, doi:10.1007/s00382-011-1044-y.

Pfahl, S., and H. Wernli, 2012: Quantifying the relevance of cyclones for precipitation extremes. J. Climate, 25, 6770-6780, doi:10.1175/JCLI-D-11-00705.1.

Polvani, L. M., M. Previdi, and C. Deser, 2011: Large cancellation, due to ozone recovery, of future Southern Hemisphere atmospheric circulation trends. Geophys. Res. Lett., 38, L04707, doi:10.1029/2011GL046712.

Raible, C. C., P. M. Della-Marta, C. Schwierz, H. Wernli, and R. Blender, 2008: Northern Hemisphere extratropical cyclones: A comparison of detection and tracking methods and different reanalysis. Mon. Wea. Rev., 136, 880-897, doi:10.1175/ 2007MWR2143.1.

Rudeva, I., and I. Simmonds, 2015: Variability and trends of global atmospheric frontal activity and links with large-scale modes of variability. J. Climate, 28, 3311-3330, doi:10.1175/JCLI-D-14-00458.1.

Simmonds, I., and K. Keay, 2000: Variability of Southern Hemisphere extratropical cyclone behavior, 1958-97. J. Climate, 13, 550-561, doi:10.1175/1520-0442(2000)013<0550:VOSHEC > 2.0.CO;2. 
, and E.-P. Lim, 2003: Synoptic activity in the seas around Antarctica. Mon. Wea. Rev., 131, 272-288, doi:10.1175/ 1520-0493(2003)131<0272:SAITSA > 2.0.CO;2.

Sinclair, M. R., 1995: A climatology of cyclogenesis for the Southern Hemisphere. Mon. Wea. Rev., 123, 1601-1619, doi:10.1175/1520-0493(1995)123<1601:ACOCFT>2.0.CO;2.

Taylor, K. E., R. J. Stouffer, and G. A. Meehl, 2012: An overview of CMIP5 and the experiment design. Bull. Amer. Meteor. Soc. 93, 485-498, doi:10.1175/BAMS-D-11-00094.1.

Thompson, D. W. J., and S. Solomon, 2002: Interpretation of recent Southern Hemisphere climate change. Science, 296, 895-899, doi:10.1126/science. 1069270 .

Ulbrich, U., G. Leckebusch, and J. Pinto, 2009: Extra-tropical cyclones in the present and future climate: A review. Theor. Appl. Climatol., 96, 117-131, doi:10.1007/s00704-008-0083-8.

- and Coauthors, 2013: Are greenhouse gas signals of Northern Hemisphere winter extra-tropical cyclone activity dependent on the identification and tracking algorithm?Meteor. Z., 22, 61-68, doi:10.1127/0941-2948/2013/0420.

Wallace, J. M., G.-H. Lim, and M. L. Blackmon, 1988: Relationship between cyclone tracks, anticyclone tracks, and baroclinic waveguides. J. Atmos. Sci., 45, 439-462, doi:10.1175/ 1520-0469(1988)045<0439:RBCTAT $>2.0 . C O ; 2$.

Wang, X. L., Y. Feng, R. Chan, and V. Isaac, 2016: Intercomparison of extra-tropical cyclone activity in nine reanalysis datasets. Atmos. Res., 181, 133-153, doi:10.1016/ j.atmosres.2016.06.010.

Wei, L., and T. Qin, 2016: Characteristics of cyclone climatology and variability in the Southern Ocean. Acta Oceanol. Sin., 35, 59-67, doi:10.1007/s13131-016-0913-y.

Willison, J., W. A. Robinson, and G. M. Lackmann, 2013: The importance of resolving mesoscale latent heating in the North Atlantic storm track. J. Atmos. Sci., 70, 2234-2250, doi:10.1175/ JAS-D-12-0226.1.

Yin, J. H., 2005: A consistent poleward shift of the storm tracks in simulations of 21st century climate. Geophys. Res. Lett., 32, L18701, doi:10.1029/2005GL023684.

Zappa, G., L. C. Shaffrey, K. I. Hodges, P. G. Sansom, and D. B. Stephenson, 2013: A multimodel assessment of future projections of North Atlantic and European extratropical cyclones in the CMIP5 climate models. J. Climate, 26, 5846-5862, doi:10.1175/JCLI-D-12-00573.1. 